\title{
Power and energy management of grid/PEMFC/battery/supercapacitor hybrid power sources for UPS applications
}

\author{
Yuedong Zhan ${ }^{a,}$, Youguang Guo ${ }^{b}$, Jianguo Zhu ${ }^{b}$ and $\mathrm{Li} \mathrm{Li}^{\mathrm{a}}$ \\ ${ }^{a}$ Department of Automation, Kunming University of Science and Technology \\ Kunming, 650500, China \\ ${ }^{\mathrm{b}}$ School of Electrical, Mechanical and Mechatronic Systems, University of \\ Technology, Sydney \\ PO Box 123, Broadway, NSW 2007, Australia \\ (Emails:ydzhan@163.com,youguang.guo-1@uts.edu.au,Jianguo.zhu@uts.edu.au) \\ *Corresponding author: Tel.: +86 871 5623806; Fax: +86 871 5916643, Email \\ address: ydzhan@163.com (Yuedong Zhan)
}

\begin{abstract}
This paper presents a hybrid power and energy source supplied by a proton exchange membrane fuel cell (PEMFC) as the main power source in an uninterruptible power supply (UPS) system. To prevent the PEMFC from fuel starvation and degradation and realize their seamless linking in the hybrid UPS system, the power and energy are balanced by the battery and/or supercapacitor (SC) as two alternative auxiliary power sources. Based on the modeling and sizing of hybrid power and energy components, the power and energy management strategies and efficiency measurements of four operating modes in UPS system are proposed. To evaluate the proposed strategies, an
\end{abstract}


experimental setup is implemented by a data acquisition system, a PEMFC generating system, and an UPS system including AC/DC rectifier, DC/AC inverter, DC/DC converter, AC/DC recharger and its intelligent control unit. Experimental results with the characteristics of a 300W self-humidified air-breathing of PEMFC, 3-cell 12V/5Ah of batteries, and two 16-cell $120 \mathrm{~F} / 2.7 \mathrm{~V}$ of SCs in parallel corroborate the excellent management strategies in the four operating modes of UPS system, which provides the basis for the optimal design of the UPS system with hybrid PEMFC/battery/SC power sources.

Keywords: Power and energy management; Proton exchange membrane fuel cell (PEMFC); Lead-acid battery; Supercapacitor (SC); Uninterruptible power supply (UPS) system

\section{Introduction}

An uninterruptible power supply (UPS) system based on traditional batteries only is hard to provide sufficient backup power to critical loads, especially when relatively long time supply is necessary. Other energy sources and storage technologies, such as a proton exchange membrane fuel cells (PEMFC) and liquid-fed direct methanol fuel cell (DMFC), have been investigated to replace the batteries. Since the PEMFCs can provide electrical power with high energy density, high efficiency and no pollution, they are considered as a promising technology for UPS products. Hence, compared with other energy storage devices, such as battery and supercapacitor (SC), the PEMFCs can offer longer continuous run-time of 24 hours and greater durability in harsh outdoor environments under a wide range of temperature conditions. Compared with conventional internal combustion generators, the PEMFCs are quieter and have low or zero emissions depending on fuel source. Because the PEMFCs are modular, UPS systems using them can be more readily sized to fit a wider variety of sites than those 
using conventional generators [1].

The PEMFCs are emerging as an economically viable option for providing UPS systems, which play a very important role as the backup and emergency power supply for important applications, particularly for computers, medical/life support systems, communication systems, office equipment, hospital instruments, industrial controls and integrated data center to supply uninterruptible and reliable power with constant voltage and frequency in case of power failure [2, 3]. For instance, US Department of Energy (DOE) funded 18 fuel cell (FC) backup power systems at 10 installation sites will help accelerate the deployment of clean technology at Federal government facilities and provide valuable data and feedback for FCs [4].

When the utility grid power source is interrupted, the hydrogen will be supplied to the PEMFCs stack in a UPS system. One of the main weak points of the PEMFCs, however, is slow dynamic characteristics administrated by the fuel transport system, such as the air and water pumps, control valves, pressure devices, mass flow devices, and a hydrogen reformer. During the start-up of PEMFCs stack, or a sudden change of external load, the hydrogen cannot be fed in time, and the stack may take a few seconds to reach the required output voltage. As a result, fast load demand for the PEMFCs will lead to a high voltage drop in a short time, which is recognized as a fuel starvation and causes the degradation of FC. So, to overcome this issue, a PEMFC should be used as the main power source in the UPS and vehicles applications. And at least a rechargeable battery or a SC must be employed as an auxiliary power source to improve the performance and prevent the PEMFC stack from degradation when the external loads demand a high energy in a short time. It should ensure the enough fuel and battery/SC capacity for providing the power needed by the external load [5]. 
The power control and energy management of hybrid power sources have already been studied recently. For instant, Thounthong et al. [6] proposed a perfect energy source supplied by a PEMFC as the main power source and storage devices: battery and SC, for modern distributed generation system, particularly for future fuel cell vehicle applications. Zhang et al. [7] proposed a seamless transfer control strategy by using a power management unit, which was suitable for FC-UPS. García et al. [8] presented a comparative study performed in order to select the most suitable control strategy for high-power electric vehicles powered by FC, battery and SC, in which each energy source uses a DC/DC converter to control the source power and adapt the output voltage to the common DC bus voltage, from where the vehicle loads are supplied. Torreglosa et al. [9] evaluated a hybrid power-train based on FC, battery and SC for a tramway, which currently operates in the city of Zaragoza, Spain. Kyriakarakos et al. [10, 11] presented an agent system for the multi-generation micro-grid topology which also included the fuzzy logic and gray prediction algorithms for better management respectively. Feroldi et al. [12] presented an energy management strategy for a sustainable hybrid system, which is based on wind-solar energy and bioethanol.

The major topology of parallel structures for a PEMFC/battery/SC hybrid power sources UPS system is shown in Fig. 1, in which the three DC/DC converters in parallel is widely used. In this paper, in order to reduce the cost, improve the performance, and decrease the losses for the UPS system, a structure of grid/PEMFC/battery/SC hybrid power system is proposed in a high-frequency single-phase small-power UPS system as depicted in Fig. 2. In Fig. 2, the outputs of PEMFC, batteries and/or SCs are linked in parallel, and the outputs of power and energy are controlled intelligently by power switches $\mathrm{K}_{0}-\mathrm{K}_{6}$ (thyristors) through the energy management and power control system. 


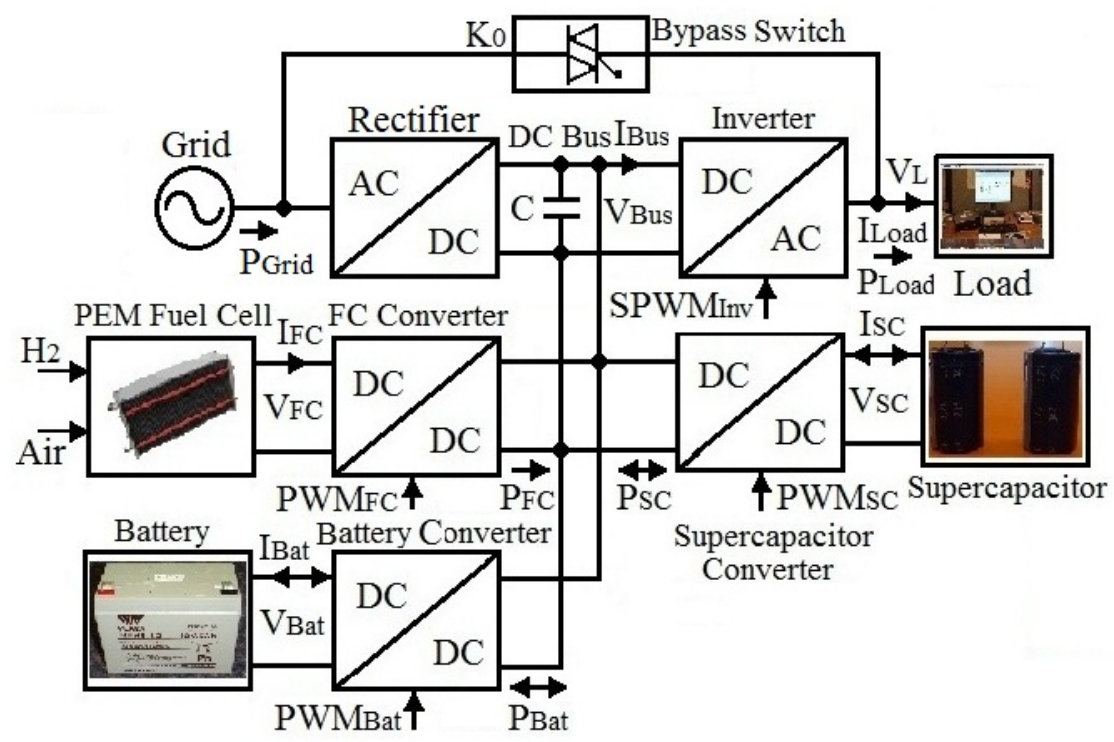

Fig. 1. Traditional structure of PEM fuel cell/battery/SC hybrid power source

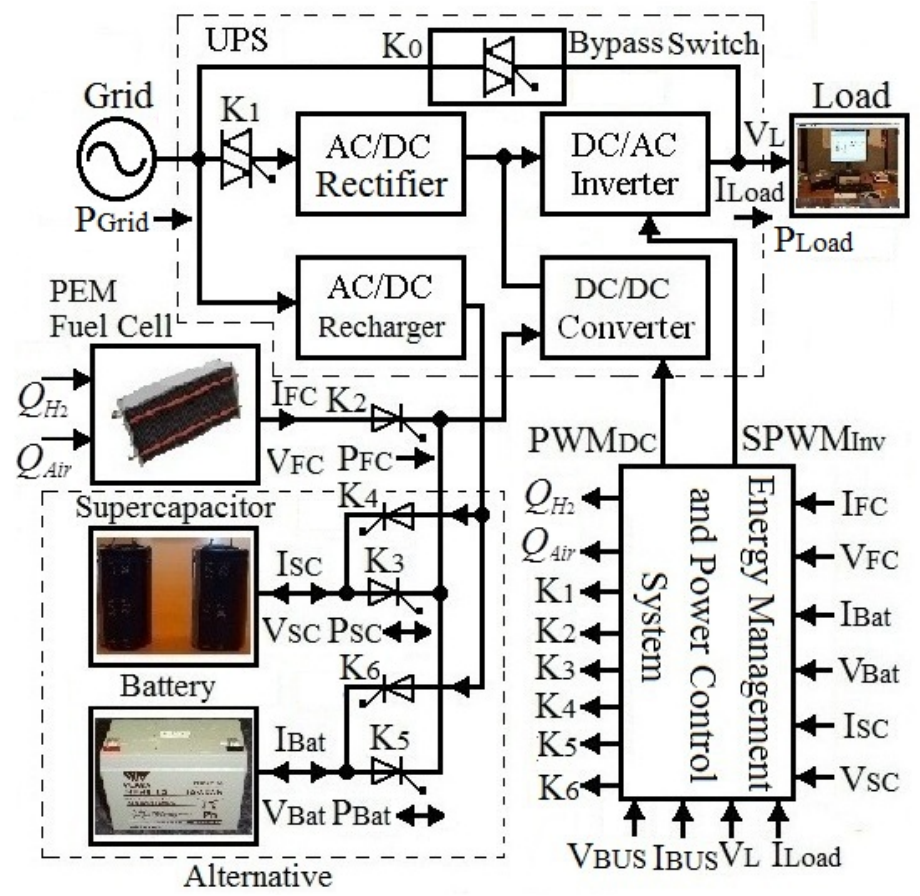

Fig. 2. Proposed structure of grid/fuel cell/battery/SC hybrid power source in UPS

\section{Modeling of hybrid power and energy system}

\subsection{Voltage model of PEMFC}


Because the PEMFC is a type of electrochemical energy conversion device, if the parameters for each single cell are lumped to represent the stack, the output voltage of the stack can be obtained as [13]

$$
\begin{aligned}
V_{\text {Stack }} & =E_{\text {reversible }}-V_{\text {actLOSS }}-V_{\text {OhmicLOSS }}-V_{\text {concLOSS }}-V_{\text {leakLOSS }} \\
& =E_{\text {reversible }}-N\left\{\frac{R T}{\alpha F} \ln \left(\frac{i+i_{n}}{i_{0}}\right)+R_{\text {Ohmic }}\left(i+i_{n}\right)+\frac{R T}{n F} \ln \left[\frac{i_{L}}{i_{L}-\left(i+i_{n}\right)}\right]\right\}
\end{aligned}
$$

where $E_{\text {reversible }}$ is the reversible voltage $(\mathrm{V})$; $V_{\text {actLOss }}$ the activation voltage loss $(\mathrm{V})$; $V_{\text {OhmicLOSS }}$ the Ohmic voltage loss $(\mathrm{V}) ; V_{\text {concLOss }}$ the concentration voltage loss (V); $V_{\text {leakLOSS }}$ the leakage voltage loss (due to internal current) $(\mathrm{V}) ; N$ the number of cells in a PEMFC stack; $\alpha$ the transfer coefficient; $n$ the number of electrons per molecule of $\mathrm{H}_{2}$ (2 electrons per molecule); $R$ the universal gas constant $\left(\mathrm{J} \cdot \mathrm{mol}^{-1} \cdot \mathrm{K}^{-1}\right) ; T$ the stack temperature $(\mathrm{K}) ; \quad F$ the Faraday's constant $\left(\mathrm{C} \cdot \mathrm{mol}^{-1}\right) ; R_{\text {Ohmic }}$ the area-normalized resistance, also known as area specific resistance (ARS) of the PEMFC measured $\left(\Omega \cdot \mathrm{cm}^{2}\right) ; i_{0}$ the exchange current density $\left(\mathrm{A} \cdot \mathrm{cm}^{-2}\right) ; i_{L}$ the limiting current density at which the cell voltage will fall rapidly $\left(\mathrm{A} \cdot \mathrm{cm}^{-2}\right)$; $i_{n}$ the internal current or parasitic current density that is wasted $\left(\mathrm{A} \cdot \mathrm{cm}^{-2}\right)$; and $i$ the PEMFC stack current density $\left(\mathrm{A} \cdot \mathrm{cm}^{-2}\right)$.

The reversible voltage at varying temperatures and pressures can be expressed as

$$
E_{\text {reversible }}=N\left\{E^{0}+\frac{R T}{2 F} \ln \left[\frac{P_{\mathrm{H}_{2}}\left(P_{\mathrm{O}_{2}}\right)^{1 / 2}}{P_{\mathrm{H}_{2} \mathrm{O}}}\right]+\frac{\Delta \bar{S}_{298.15 K}}{n F}(T-298.15)\right\}
$$

where $P_{i}$ is the partial pressure of species $i$ ( $i$ is $\mathrm{H}_{2}, \mathrm{O}_{2}$ /air, or liquid water at cathode side) $(\mathrm{kPa})$, respectively; $E^{0}$ the cell open-circuit voltage (OCV) at the standard temperature and pressure (STP); and $\Delta \bar{S}_{298.15 K}$ the change in the molar entropy at STP $\left(\mathrm{J} \cdot \mathrm{mol}^{-1} \cdot \mathrm{K}^{-1}\right)$ 
According to the above voltage output equation, an equivalent circuit for electrochemical circuit model of PEMFC is obtained, as shown in Fig. 3, where $C$ is the equivalent capacitor due to the double-layer charging effect $(\mathrm{F}) ; V_{c}$ the voltage across the capacitor $(\mathrm{V}) ; \quad R_{\text {act }}$ the activation resistance $(\Omega)$; and $R_{\text {conc }}$ the concentration resistance $(\Omega)$.

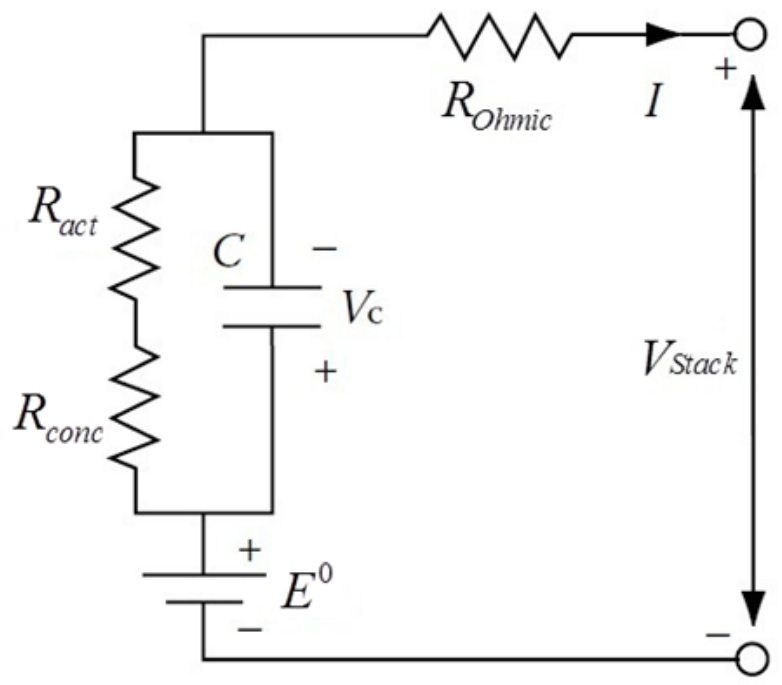

Fig. 3. Equivalent circuit of a PEMFC

\subsection{Power and energy model of PEMFC}

The hydrogen and oxygen/air are fed to the PEMFC generating system at an appropriate rate according to the current and voltage drawn from the external load of UPS. Air on the cathode side is often supplied with a higher stoichiometric flow rate because the cathode reaction is much slower than the anode reaction. Since using an air-breathing and self-humidified PEMFC in UPS system, and the PEMFC voltage heavily relies on the air stoichiometric flow rate, the role of the fans is very important to blow more air through the system. Three air fans with an optimal speed can supply varying amounts of air for the power and inside temperature demand.

According to the real-time current and voltage measurements of PEMFC stack based on the loads of UPS, the power (ranging from 12 to $330 \mathrm{~W}$ ) can be firstly calculated. The 
output power of the stack can be calculated by

$$
P_{\text {Stack }}=V_{\text {Stack }} I
$$

where $P_{\text {Stack }}$ is the output power $(\mathrm{W}), V_{\text {Stack }}$ the output voltage $(\mathrm{V})$, and $I$ the output current of the stack $(A)$.

Based on the external load at that time, an energy supply system of hydrogen and air is designed to continuously distribute the current or real-time power by using the setup value of the reference mass flow $Q^{\text {ref }}{ }_{\mathrm{H} 2}$ and $Q^{\text {ref }}{ }_{\mathrm{O} 2}$ of hydrogen and air, according to the stoichiometric ratios of PEMFC. The mass flow rates of hydrogen and air for the stack can be calculated as follows.

\subsubsection{Hydrogen mass flow rate}

At the standard conditions of the atmospheric pressure and temperature of $25^{\circ} \mathrm{C}$, the molar volume is

$$
V_{m}=\frac{R T}{P}=\frac{8.314 \times 278.15}{101,300}=0.0228 \mathrm{~m}^{3} / \mathrm{mol}=22.8 \mathrm{~L} / \mathrm{mol}
$$

The reference volumetric flow rate of pure hydrogen consumption in standard liters per minute or SL/min (SLPM) is

$$
Q_{H_{2}}^{r e f}=22.8 \times 60 \times \frac{N \cdot I}{2 F} \times S_{H_{2}}
$$

where $S_{H_{2}}$ is the stoichiometry ratio of hydrogen, which is selected within 1.2 1.5.

According to the hydrogen mass flow controller designed by fuzzy logic control rules, the hydrogen flow rate varies between 0 and $4.7 \mathrm{SL} / \mathrm{min}$ at stoichiometric ratio of 1.2 and under the current variations of 0 to $9 \mathrm{~A}$, while the air flow rate is supplied by the three fans. The hydrogen flow rate can keep tracking the reference value given by power tracking controller. 


\subsubsection{Air mass flow rate}

Because the PEMFC stack selected is an air-breathing and air-cooling FC, that is, air is passing through the cathode compartment in excess of oxygen exact stoichiometry, and the same air is used as a coolant. In the PEMFC generating system, the air is supplied by three blowers that are used to cool the stack. The air volumetric mass flow rate in $\mathrm{SL} / \mathrm{min}$ is [14]

$$
Q_{O_{2}}^{r e f}=22.8 \times 60 \times \frac{M_{A i r} N \cdot I}{4 F} \times S_{O_{2}}
$$

where $M_{\text {Air }}$ is the air mass (kg) and $S_{\mathrm{O}_{2}}$ is the required air stoichiometric ratio, which is calculated theoretically as follows and selected within 20 30 by experience.

According to the dynamic analysis of the PEMFC, because of the electrochemical reaction, if the water produced in the PEMFC stack evaporates and leaves the stack as vapor, the heat generated is

$$
Q=\left(1.254-V_{\text {cell }}\right) N \cdot I
$$

where $V_{\text {cell }}$ is the cell voltage $(\mathrm{V})$.

According to the Fourier's law, the heat transferred to air is

$$
Q=\dot{m}_{A i r} c_{p} \Delta T
$$

where $\dot{m}_{\text {Air }}$ is the air mass flow rate $(\mathrm{kg} / \mathrm{s}), \Delta T$ the air temperature difference between the inlet and outlet of the stack (K), $c_{p}$ the heat capacity $(\mathrm{J} / \mathrm{kg} \mathrm{K})$, which may be expressed by an empirical relationship as $c_{p}=a+b T+c T^{2}$, and $a, b$ and $c$ are the empirical coefficients.

The air mass flow rate at the stack exit is given by 


$$
\dot{m}_{\text {Air }}=\left[\left(S_{\mathrm{O}_{2}}-1\right) M_{\mathrm{O}_{2}}+S_{\mathrm{O}_{2}} \frac{1-r_{\mathrm{O}_{2}}}{r_{\mathrm{O}_{2}}} M_{N_{2}}\right] \frac{N \cdot I}{4 F}
$$

where $M_{\mathrm{O}_{2}}$ is the oxygen mass $(\mathrm{kg}), M_{N_{2}}$ the nitrogen mass $(\mathrm{kg})$, and $r_{\mathrm{O}_{2}}$ the oxygen volume or molar fraction in the stack inlet.

According to (7), (8), and (9), the required air stoichiometric ratio is

$$
S_{\mathrm{O}_{2}}=\frac{M_{\mathrm{O}_{2}}+\frac{4 F\left(1.254-V_{\text {cell }}\right)}{c_{p} \Delta T}}{M_{\mathrm{O}_{2}}+\frac{1-r_{\mathrm{O}_{2}}}{r_{\mathrm{O}_{2}}} M_{N_{2}}}
$$

In the designed PEMFC generating system, the air mass flow rate guarantees the enough air supply for the stack, and the air supply and thermal controller keep the temperature of the stack in the range of the $46 \sim 55^{\circ} \mathrm{C}$. With the increase of the load, the temperature of stack will go up as soon as possible to obtain a better performance. In general, higher operating temperature is desirable due to decreased mass transport limitations and increased electrochemical reaction rates. Simultaneously, the high temperatures may lead to increase mass transport losses due to the increase of water vapor and damage the membrane. When the load decreases sharply, the air supply and thermal controller must adjust the fan speed quickly to avoid the drying and degradation of membrane. Thus, in the PEMFC generating system, the stack temperature is controlled in the range of $46 \sim 55^{\circ} \mathrm{C}$, in order to keep the water balance and reduce the effect of the internal resistance or Ohmic losses [13].

\subsection{Modeling of SC}

A SC is a type of electrochemical energy storage device, which is an electrochemical capacitor that has an unusually high energy density when compared to common 
capacitors, typically thousands times greater than that of a high capacity electrolytic capacitor. It also has almost $90 \%$ of high cycle efficiency. Because the SCs can improve storage density through the use of a nano-porous material, two very high surface area porous electrodes are soaked in electrolyte, and the charge is stored in electrochemical double layers.

Due to the structure of a SC, the boundary conditions are shown in Fig. 4. On the surface contacting with a separator, electron flux is not allowed and the normal component of potential gradient in solid material is zero. In the similar manner, on the surface contacting with a current collector, ion flux is not allowed and the normal component of potential gradient in electrolyte is zero. The potential in electrolyte at the surface contacting a separator is set to be the zero reference value. And the potential may be a function of time, in conducting solid material at the surface contacting a current collector [15].

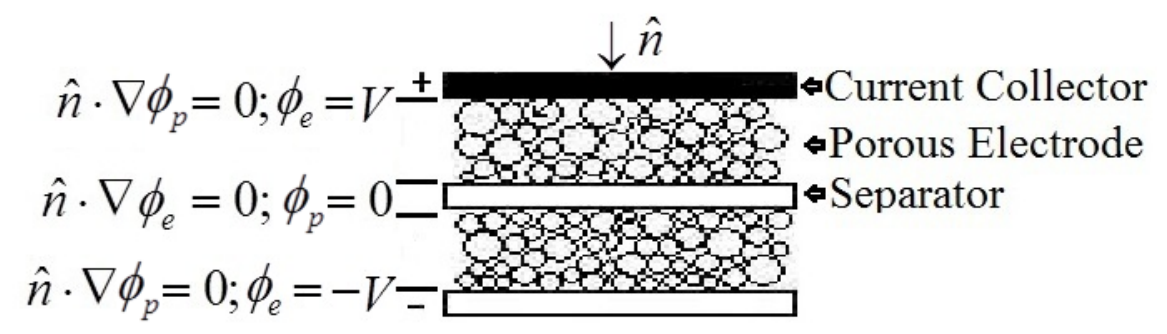

Fig. 4. Boundary conditions for macroscopic potentials in an SC

A SC can be modeled as an RC transmission line model, shown in Fig. 5. Assume a symmetric situation of two identical porous electrodes of thickness $L$, and focus on only one, in the region $0<x<L$. The electrolyte-filled pore space has a constant volume-averaged resistance per length $R$ and constant capacitance per unit length $C$. Neglect any resistance in the porous electrode or the thin gap between the electrodes. The mean potential in the pores satisfies a linear diffusion equation as 


$$
\frac{1}{\mathrm{R}_{e}} \nabla^{2} \phi_{e}=-\frac{1}{R_{p}} \nabla^{2} \phi_{p}=C \frac{\partial\left(\phi_{e}-\phi_{p}\right)}{\partial t}
$$

where $\phi_{e}(x, t)$ is the electron potential $(\mathrm{V}) ; \phi_{p}(x, t)$ the ion potential $(\mathrm{V}) ; R_{e}=\frac{1}{A \bar{\sigma}_{e}}$ the electron resistance per length $\left(\Omega \cdot \mathrm{cm}^{-1}\right) ; R_{p}=\frac{1}{A \bar{\sigma}_{p}}$ the ion resistance per length $\left(\Omega \cdot \mathrm{cm}^{-1}\right)$; $C=A a_{p} C_{D}$ the double layer capacitance per length $(\mathrm{F} \cdot \mathrm{cm})$, where $\bar{\sigma}_{e}$ is macroscopic electron conductivity in conducting phase $\left(\Omega^{-1} \cdot \mathrm{cm}^{-1}\right) ; \bar{\sigma}_{p}$ the macroscopic ionic conductivity in pores $\left(\Omega^{-1} \cdot \mathrm{cm}^{-1}\right) ; a_{p}$ the double layer capacitance per volume $\left(\mathrm{F} \cdot \mathrm{cm}^{-2}\right) ; A$ the macroscopic electrode area $\left(\mathrm{cm}^{2}\right)$; $L$ the electrode length from separator to current collector (cm); and $C_{D}$ a double layer capacitance model coefficient.

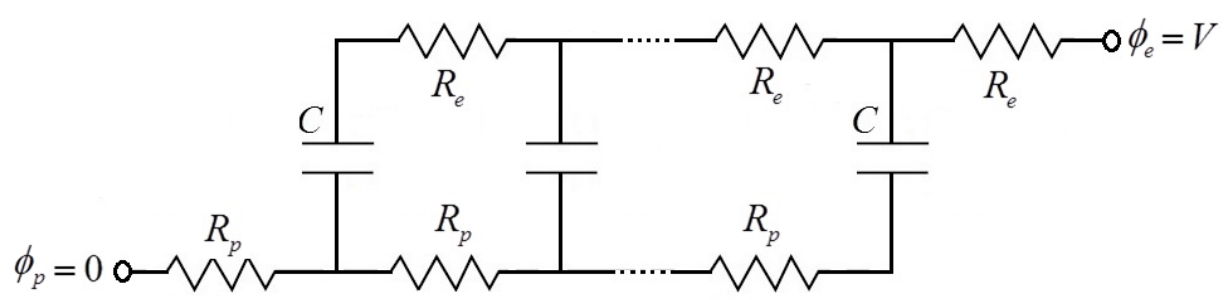

Fig. 5. Transmission line equivalent circuit model of an SC

Equally, a simple model of the SC can be developed in a similar way as that of the lead-acid battery as mentioned below. The voltage $V_{S C}$ and current $I_{S C}$ are [16]

$$
\begin{gathered}
V_{S C}=N_{C}^{s}\left(V_{0}-R_{\text {cell }} I_{S C}\right) \\
I_{S C}=N_{C}^{p} I_{\text {cell }} \\
V_{0}=V_{c}=\frac{\Delta Q}{C_{\text {cell }}} \\
\Delta Q=I_{\text {cell }} T_{C}^{s}
\end{gathered}
$$

where $V_{0}$ is the OCV $(\mathrm{V})$, which has the same role as the SC voltage $V_{C} ; \Delta Q$ the changing amounts of the electrical charge (C); $I_{\text {cell }}$ the cell current of SC (A); $T_{C}^{s}$ the 
discharging time (s); $N_{C}^{s}$ the number of cells for SC in series; and $N_{C}^{p}$ the number of series-cells for SC in parallel.

Another type of the equivalent circuit is also similar to the lead-acid battery model shown in Fig. 6, where $R_{\text {selfd }}$ indicates the self-discharge resistance of the $\mathrm{SC}(\Omega)$.

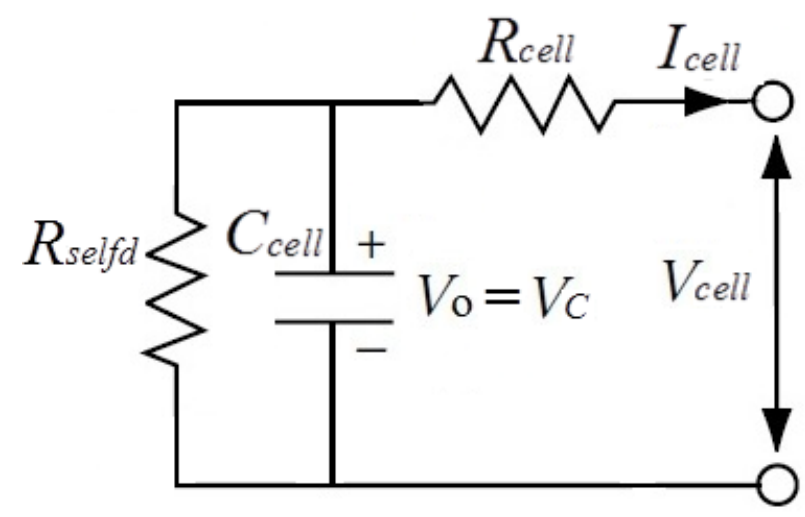

Fig. 6. Equivalent circuit of SC

\subsection{Modeling of lead-acid batteries}

The lead-acid batteries or secondary batteries are a kind of electrochemical energy storage devices, known as the rechargeable batteries which store energy in the electrochemical form. The use of high-capacity lithium-ion rechargeable batteries have been recommended in the various applications such as electric, hybrid electric vehicles and hybrid power systems including the backup power source. Because of the cost and charging issues, however, the sealed lead-acid (Pb-acid) and the vented $\mathrm{Ni}$-Cd batteries previously used by various commercials should be widely deployed to meet improved efficiency, reliability, longevity, and output power requirements.

Because it is extremely difficult to build and understand the dynamic modeling of a lead-acid battery, in this paper, a simple battery model is introduced. The battery current $I_{\text {Bat }}$ as function of the required battery power $P_{\text {Bat }}$, the internal resistance $R_{\text {Bat }}$ and the OVC voltage $E_{0}$ is [16] 


$$
\begin{gathered}
V_{\text {Bat }}=E_{0}-R_{\text {Bat }} I_{\text {Bat }} \\
P_{\text {Bat }}=V_{\text {Bat }} I_{\text {Bat }} \\
I_{\text {Bat }}=\frac{E_{0}-\sqrt{E_{0}^{2}-4 P_{\text {Bat }} R_{\text {Bat }}}}{2 R_{\text {Bat }}}
\end{gathered}
$$

where based on the empirical Peukert's law, $E_{0}=N_{B}^{s} f\left(S O C, T^{0}\right)$, $R_{B a t}=\frac{N_{B}^{s}}{N_{B}^{p}} f\left(S O C, T^{0}\right), \quad S O C=1-\frac{I_{B a t} T_{B}^{s}}{3600 C_{5}}\left(\frac{I_{B a t}}{I_{5}}\right)^{k-1} \cdot N_{B}^{s}$ is the number of cells in series; $N_{B}^{p}$ the number of series-cells in parallel; $T^{0}$ the cell temperature $\left({ }^{\circ} \mathrm{C}\right)$; SOC the state of charge (\%); $C_{I}$ the relative remaining capacity of the battery, e.g. $C_{5}$ the 5-h rate capacity, in the number of Ampere-hours (Ah); $T_{B}^{s}$ the discharging time of battery (s); and $k$ the Peukert number.

According to the above voltage output equation, an equivalent circuit for electrochemical circuit model of lead-acid battery is obtained, as shown in Fig. 7.

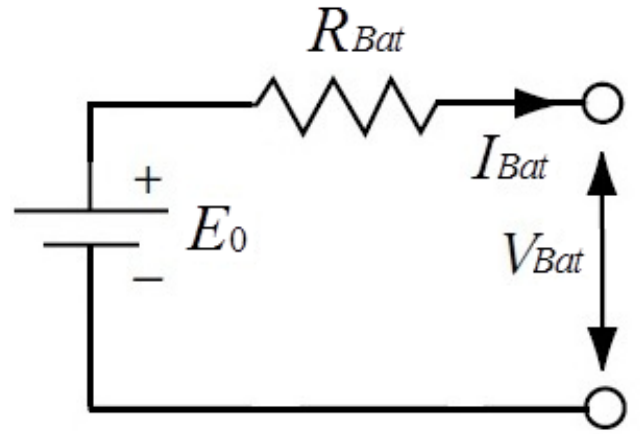

Fig. 7. Equivalent circuit of a lead-acid battery

\section{Power Sizing of hybrid UPS system}

In order to meet the demand of the technical reliability and calculate the life cycle costs of the system, the sizing of an UPS hybrid power system will be dealt with the aim of obtaining a cost efficiency system according to any defined hourly load profile and any 
defined backup time. A solution is defined by PEMFC, SC and battery sizes and the energy management strategy.

\subsection{Power sizing of PEMFC}

In this UPS hybrid power system using PEMFC as backup power source, a 300W single-phase high-frequency low-loss smart UPS has been designed, with nominal voltage of 36V; minimum supply voltage of $30 \mathrm{~V}$; efficiency of 0.9 ; maximum load of 270W; backup time of 24 hours for PEMFC; backup time of 15 s for SC; and backup time 20 min for battery.

The PEMFC size is the largest, the fuel cell capital cost is the highest, and the battery and SC requirements are the least restrictive. Thus, in order to release a $24 \mathrm{~h}$ continuous backup operation mode, according to its working voltage of $31.5-56.7 \mathrm{~V}$, a $300 \mathrm{~W}$ (36V/8.4A) air-breathing air-cooling self-humidified PEMFC is employed to supply the main power source for UPS system.

Because the PEMFC stack is a new type of self-humidified, air-breathing and air-cooling together, some parameters are confidential to the manufacturer of the stack such as the anode volume, cathode volume and so on, we have done some experiments, but no simulations. The basic experimental conditions of PEMFC are: hydrogen maximum input flow of $3.9 \mathrm{~L} / \mathrm{min}$; hydrogen pressure of $50-55 \mathrm{kPa}$; number of cells of 63; effective area of $18 \mathrm{~cm}^{2}$; start up time of $10 \mathrm{~s}$ under the condition of constant voltage; and maximum stack temperature of $55^{\circ} \mathrm{C}$.

\subsection{Power sizing of lead-acid battery}

Because the PEMFC is the main power source and lead-acid battery is used as the auxiliary power source in the UPS system, based on minimum cost profile, the sizing of 
battery is designed taking into account the PEMFC start-up time of $10 \mathrm{~s}$ and maintaining time of 10 min when PEMFC fails.

Based on the demand of UPS system, 3-cell Yuasa ${ }^{\circledR}$ NP deep cycle lead-acid batteries, with nominal voltage of $12 \mathrm{~V}$, are selected. Based on the rated power of $270 \mathrm{~W}$, minimum discharging voltage of $V_{\min }=30 \mathrm{~V}$ and the efficiency of UPS system designed of $\eta=0.9$, the discharging current is

$$
I=\frac{P}{V_{\min } \eta}=\frac{270}{30 \times 0.9}=10(A)
$$

Because of the requirement of the battery discharging time of $10 \mathrm{~min}$ and the minimum discharging voltage of $10 \mathrm{~V}$ for a lead-acid battery, according to the typical discharging characteristics of batteries at an ambient temperature of $25^{\circ} \mathrm{C}$ through the discharge current rates and the discharge time, the discharging current ratio approximately equals 2 CA, and the battery capacity selected is [17]

$$
A h=\frac{A}{C A}=\frac{10}{2}=5
$$

On the other hand, according to the recommended calculation method of battery size required for constant power load conditions, calculating the battery capacity from the list is $4.46 \mathrm{Ah}$, which is the minimum requirement.

At present, the lead-acid battery has two types of products: deep cycle battery and gel battery. Based on the cost factor, we selected 3-cell series-connected deep cycle lead-acid batteries with the main specifications as NPH5-12, 12V/5Ah/10HR, and $R_{\text {Bat }}=0.043 \Omega, N_{B}^{s}=3, N_{B}^{p}=1$.

\subsection{Power sizing of SC}

The SC is used as a type of auxiliary power source in the UPS system, according to the 
maximum charging voltage of $41 \mathrm{~V}$, in which the recommended float voltage for NP batteries at $25^{\circ} \mathrm{C}$ is $2.26 \mathrm{~V}$ per cell from the UPS system, and the voltage of $V_{\text {cell }}=2.7 \mathrm{~V}$ for single cell SC, the number of SCs designed in series equals

$$
N_{C}^{s}=\frac{V_{\max }}{V_{\text {cell }}}=\frac{41}{2.7}=16
$$

Selecting the discharging time as $T_{C}^{s}=15 \mathrm{~s}$, and taking into account the start-up time of more than $10 \mathrm{~s}$ for PEMFC, and $C=120 F, R_{\text {cell }}=0.02 \Omega$, according to the equivalent circuit in $\quad$ Fig. $8, \quad$ and then $R_{\text {Load }}=3 \Omega$, $R_{\text {eq }}=N_{C}^{s} R_{\text {cell }} / / N_{C}^{s} R_{\text {cell }} / / \cdots / / N_{C}^{s} R_{\text {cell }}\left(N_{C}^{p}\right.$ times $)=\frac{N_{C}^{s}}{N_{C}^{p}} R_{\text {cell }}$, and $C_{e q}=\frac{N_{C}^{p}}{N_{C}^{s}} C_{\text {cell }}$.

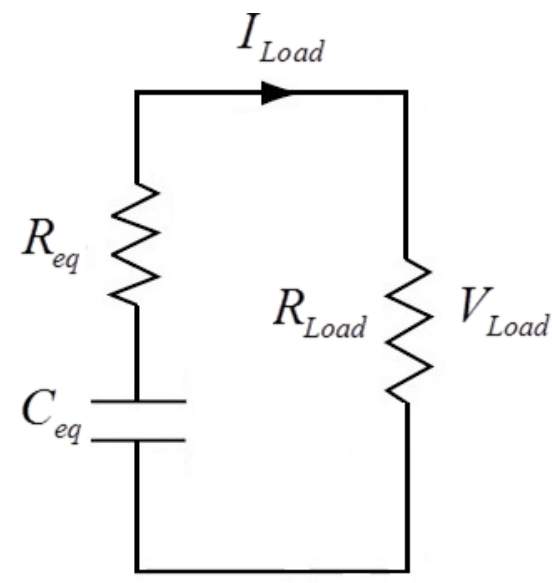

Fig. 8. Equivalent circuit of SCs in parallel and in series

Because $V_{C}\left(0^{-}\right)=V_{C}\left(0^{+}\right)=41 V$, and $V_{C}(\infty)=0$, the SC voltage is

$$
\begin{aligned}
v_{C}(t) & =\left[V_{C}(0)-V_{C}(\infty)\right] \exp \left[-\frac{t}{\left(R_{\text {eq }}+R_{\text {Load }}\right) C_{\text {eq }}}\right]+V_{C}(\infty) \\
& =V_{C}(0) \exp \left\{-\frac{t}{\left[\left(N_{C}^{s} / N_{C}^{p}\right) R_{\text {cell }}+R_{\text {Load }}\right]\left(N_{C}^{p} / N_{C}^{s}\right) C_{\text {cell }}}\right\}, t \geq 0
\end{aligned}
$$


The voltage of the load is

$$
\begin{aligned}
v_{\text {Load }}(t) & =\frac{R_{\text {Load }}}{R_{\text {eq }}+R_{\text {Load }}} v_{C}(t) \\
& =\frac{R_{\text {Load }}}{R_{\text {eq }}+R_{\text {Load }}} V_{C}(0) \exp \left\{-\frac{t}{\left[\left(N_{C}^{s} / N_{C}^{p}\right) R_{\text {cell }}+R_{\text {Load }}\right]\left(N_{C}^{p} / N_{C}^{s}\right) C_{\text {cell }}}\right\}
\end{aligned}
$$

Because $v_{\text {Load }}\left(t=T_{C}^{s}=15 s\right)=30 V, N_{C}^{s}=15$, and then the number of SCs in parallel can be calculated as $N_{C}^{p}=2$.

It follows that we select the series-connected SCs with the main specifications as HP-2R7-J127UY LR, the capacity of $C_{\text {cell }}=120 \mathrm{~F}( \pm 25 \%)$, control voltage of $2.7 \mathrm{~V}$, internal resistance $R_{\text {cell }}=0.02 \Omega( \pm 25 \%)$, and the rated current of $25 \mathrm{~A}$ under the condition of the direct current (DC).

Through the self-discharging characteristics measurements of three SCs, it is found that the average self-discharging time $\bar{t}=3763 \mathrm{~s}, V_{C}(0)=2.7 \mathrm{~V}$ and $V_{C}(\bar{t})=1.8 \mathrm{~V}$, if assuming $V_{C}(\infty)=0 \mathrm{~V}$, then the self-discharging resistance is $R_{\text {selfd }}=78.4 \Omega$.

\section{Power and energy management strategy}

The purpose of the UPS system with hybrid PEMFC/battery/SC power sources is to provide uninterruptible, reliable, and high-quality power of 24 hours to the loads. Energy management and Power control strategy for hybrid power system in UPS and automobiles applications is based on the needs of loads and operating modes. The concept of multiple hybrid power sources is to ensure a sustainable power supply for 
their system. In UPS applications, the power control and energy management strategy is dependent on the four operating modes as follows as shown in Fig. 9.

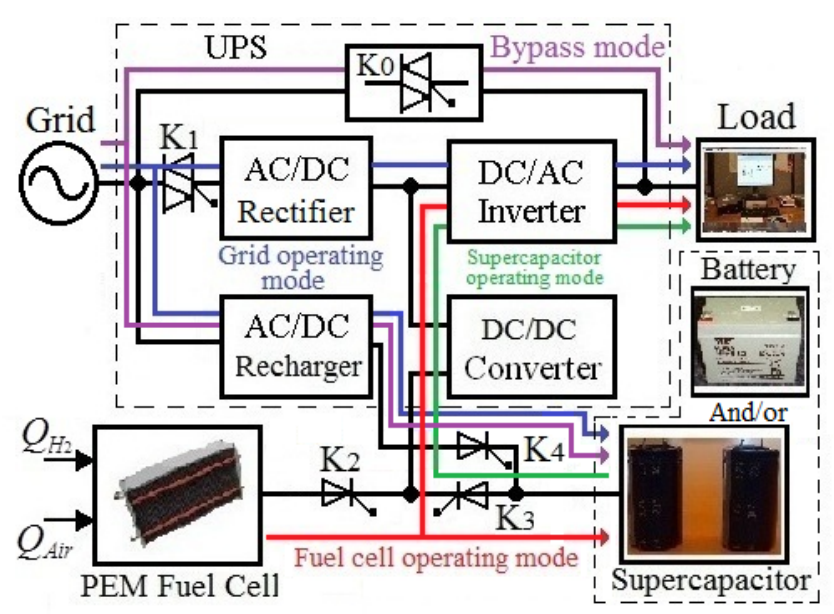

Fig. 9. Four operating modes of the proposed UPS system with grid/PEMFC/battery/SC hybrid

power sources

1) Utility grid operating mode: In this operation mode, on the one hand, the grid supplies the power sources for the load through the AC/DC rectifier and the DC/AC inverter as demonstrated in Fig. 9. On the other hand, the grid charges the batteries or SCs through the AC/DC recharger.

2) FC operating mode: In Fig. 9, when the utility grid fails, the PEMFC feeds the DC/AC inverter through the DC/DC converter because of the unstable PEMFC voltage (31.5-56.7 V), which only minds the demands of the DC/AC inverter, but does not act as the role of a traditional DC/DC converter to maintain the DC Bus voltage and balance the upper and lower capacitor voltage. The proposal DC/DC converter is a push-pull converter with active-clamp circuit and works in the double state of polarity, in which the low frequency current ripples are so low that they do not cause efficiency reduction of the PEMFC and have not a detrimental effect on its performance. Meanwhile, the PEMFC could charge the batteries or SCs according to their needs.

3) Battery/SC operating mode: In Fig. 9, when the PEMFC starts up and the external load charges sharply, the batteries or SCs feeds the DC/AC inverter through the DC/DC converter. As mentioned above, because its cold start-up time is long, or its 
dynamical response is slow, that is, for a sudden change of external load, the hydrogen cannot be fed fast enough, and the PEMFC stack may take a few seconds to reach the required output voltage, which can lead to the fuel starvation and degradation of the stack. To overcome this issue, the rechargeable batteries or SCs can be employed as the auxiliary power source to respond fast to the external load and protect the PEMFC from degradation and damage.

4) Bypass operating mode: In this operation mode, the grid feeds the load through the bypass switch as shown in Fig. 9 when the UPS starts up and the DC/AC inverter fails. Meanwhile, the grid charges the batteries or SCs through the AC/DC recharger.

\subsection{Intelligent power control and energy management strategies}

Besides the normal operating and controls of AC/DC rectifier, DC/AC inverter, DC/DC converter and AC/DC recharger in the UPS system and PEMFC generating system, in order to prevent the PEMFC from degradation and improve its performance, the developed intelligent power control and energy management strategies in the UPS system are as following and as shown in Fig. 2 and Fig. 9.

- Strategy 1: Monitoring the power and energy (voltage $V_{L}$ and current $I_{\text {Load }}$ ) of the UPS load, and deciding if the UPS is supplied by the utility grid, PEMFC, and battery or SC through the switches $K_{0}, K_{1}, K_{2}, K_{3}\left(K_{5}\right)$;

- Strategy 2: Monitoring the power changes (the changes of the voltages $V_{L}, V_{F C}$ and currents $I_{\text {Load }}, I_{F C}$ ) of the UPS load and PEMFC stack, and deciding if the UPS is supplied by the stack, or battery/SC or in parallel through the switches $K_{2}, K_{3}\left(K_{5}\right)$;

- Strategy 3: Monitoring the power (voltage $V_{L}$ and current $I_{\text {Load }}$ ) of UPS load and the energy (hydrogen mass flow rate $Q_{H_{2}}$ and air mass flow rate $Q_{\text {Air }}$ ) of PEMFC, and deciding how much fuel and air are supplied with the stack through the 
hydrogen and air mass flow rates $\left(Q_{\mathrm{H}_{2}}\right.$ and $Q_{\text {Air }}$ ) of the PEMFC controller;

- Strategy 4: Monitoring the power (voltage $V_{S C}\left(V_{B a t}\right)$ and current $I_{S C}\left(I_{B a t}\right)$ ) of the battery or SC, and deciding if the UPS is supplied by the battery or SC through the switch $K_{3}\left(K_{5}\right)$, and if the battery or SC is recharged by the AC/DC recharger or the PEMFC through the switches $K_{3}\left(K_{5}\right), K_{4}\left(K_{6}\right)$; and

- Strategy 5: Monitoring the powers (voltages $V_{L}, V_{B U S}$ and currents $I_{\text {Load }}, I_{B U S}$ ) of UPS load, output voltage $V_{B U S}$ and current $I_{B U S}$ of DC/DC converter, and deciding how many duty cycles $\left(\mathrm{SPWM}_{\text {Inv }}\right.$ and $\left.\mathrm{PWM}_{\mathrm{DC}}\right)$ of the DC/AC inverter and DC/DC converter, which conducts the coordinated control and maximum power point tracking (MPPT) control of PEMFC for the entire system and commands other parts of the system to realize the power seamless transfer and transition control and minimum power and energy control among different operating modes.

\subsection{Implementation of power control and energy management strategies}

\subsubsection{Power, energy management and efficiency of hybrid UPS system}

\subsubsection{Power management modes}

The electrical power and energy output can be easily calculated from the well-known formulas $P=V I$ and $E=P t=V I t$. As depicted in Fig. 2, if the losses of power and energy for main components (AC/DC rectifier, AC/DC recharger, DC/AC inverter, PEMFC, battery, and SC) in the system are considered, the classical power output conservative law of the grid/PEMFC/battery/SC hybrid power sources can be written as follows

$$
P_{\text {Load }}=\eta_{U P S}\left(P_{\text {Grid }}+\frac{P_{F C}}{\eta_{F C}} \pm \frac{P_{S C}}{\eta_{S C}} \pm \frac{P_{\text {Bat }}}{\eta_{\text {Bat }}}\right)
$$


where $P_{\text {Load }}$ is the load power (W); $P_{\text {Grid }}$ the grid input power (W); $P_{F C}$ the PEMFC output power supplied by the PEMFC generating system (W); $P_{S C}$ the charging or discharging power of the SC (W); $P_{B a t}$ the charging or discharging power of the battery power (W); $\eta_{\mathrm{UPS}}=\eta_{A C / D C(r t)} \eta_{A C / D C(r c)} \eta_{D C / D C} \eta_{D C / A C}$ the efficiency of UPS system, where $\eta_{A C / D C(r t)}, \eta_{A C / D C(r c)}, \eta_{D C / D C}$ and $\eta_{D C / A C}$ are the efficiency of AC/DC rectifier, AC/DC recharger, DC/DC converter and DC/AC inverter respectively; $\eta_{F C}=\eta_{f} \frac{V_{\text {cell }}}{1.48} \times 100 \%$ is the efficiency of PEMFC, where $\eta_{f}$ is the fuel utilisation defined as a ratio between the mass of fuel that reacted in the PEMFC and the mass of fuel entering the stack (typically about 0.95 ) and $V_{\text {cell }}$ the voltage of a single cell within the stack; $\eta_{S C}$ the charging/discharging efficiency of the SC; $\eta_{\text {Bat }}$ the charging/discharging efficiency of the battery; “+” the symbol for discharging of SC and battery; “-”the symbol for charging of SC and battery.

As a result, based on the different operating modes in the UPS applications, the load power comes from the different power sources: grid, PEMFC, battery and SC. The power control forms are as follows:

1) Utility grid operating mode: $P_{\text {Load }}=\eta_{U P S}\left(P_{\text {Grid }}-\frac{P_{S C}}{\eta_{S C}}-\frac{P_{\text {Bat }}}{\eta_{\text {Bat }}}\right)$

2) FC operating mode: $P_{\text {Load }}=\eta_{U P S}\left(\frac{P_{F C}}{\eta_{F C}} \pm \frac{P_{S C}}{\eta_{S C}} \pm \frac{P_{B a t}}{\eta_{B a t}}\right)$

3) Battery and/or SC operating mode: $P_{\text {Load }}=\eta_{U P S}\left(\frac{P_{S C}}{\eta_{S C}}+\frac{P_{B a t}}{\eta_{\text {Bat }}}\right)$

4) Bypass operating mode: $P_{\text {Load }}=\eta_{U P S} P_{\text {Grid }}-\frac{P_{S C}}{\eta_{S C}}-\frac{P_{B a t}}{\eta_{\text {Bat }}}$

In the developed UPS hybrid power system, the two types of main energies consumption are the electrical energy from the utility grid and the electrochemical 
energy from the PEMFC, which is the electrochemical energy conversion device. That is, hydrogen energy is converted into electrical energy and heat. However, the chemical energy of input and output of $\mathrm{H}_{2}, \mathrm{O}_{2}$, and $\mathrm{H}_{2} \mathrm{O}$ is not so easily defined, and terms such as the enthalpy, Helmholtz function, and Gibbs free energy are used. Since the PEMFC uses materials that are usually burnt to release their energy, it would make sense to compare the electrical energy produced with the heat that would be produced by burning the fuel. So the energy and efficiency of a PEMFC are defined by the electrical energy produced and the Gibbs free energy change.

\subsubsection{Energy management modes}

The SC and battery are the electrochemical energy storage devices. When their electrochemical energy systems are connected to an external source, they are charged by the electrical source from the utility grid or PEMFC and a finite charge Q is stored. So the systems convert the electric energy into the stored chemical energy in charging process. When the systems are connected to an external circuit DC/DC converter of UPS system, they release the finite Q and drive a current through the external circuit. The systems convert the stored chemical energy into electric energy in discharging process.

The energy forms of grid, PEMFC, battery and SC are almost electrical ones, and their energy equation is

$$
\frac{d E(t)}{d t}=\frac{d(Q V)}{d t}=\eta_{U P S}\left(P_{\text {Grid }}+\frac{P_{F C}}{\eta_{F C}} \pm \frac{P_{S C}}{\eta_{S C}} \pm \frac{P_{\text {Bat }}}{\eta_{\text {Bat }}}\right)-P_{\text {Load }}
$$

The energy management forms are as follows:

1) Utility grid operating mode: 


$$
\frac{d E_{\text {Grid }}(t)}{d t}=\eta_{U P S}\left(P_{\text {Grid }}-\frac{P_{S C}}{\eta_{S C}}-\frac{P_{\text {Bat }}}{\eta_{\text {Bat }}}\right)-P_{\text {Load }}
$$

2) FC operating mode: $\frac{d E_{F C}(t)}{d t}=\eta_{U P S}\left(\frac{P_{F C}}{\eta_{F C}} \pm \frac{P_{S C}}{\eta_{S C}} \pm \frac{P_{B a t}}{\eta_{\text {Bat }}}\right)-P_{\text {Load }}$

3) Battery operating mode:

$$
\frac{d E_{\text {Bat }}(t)}{d t}=\eta_{U P S} \frac{P_{\text {Bat }}}{\eta_{\text {Bat }}}-P_{\text {Load }}
$$

And/or SC operating mode:

$$
\frac{d E_{S C}(t)}{d t}=\eta_{U P S} \frac{P_{S C}}{\eta_{S C}}-P_{\text {Load }}
$$

4) Bypass operating mode: $\frac{d E_{\text {Grid }}(t)}{d t}=\eta_{U P S} P_{\text {Grid }}-\frac{P_{S C}}{\eta_{S C}}-\frac{P_{\text {Bat }}}{\eta_{\text {Bat }}}-P_{\text {Load }}$

\subsubsection{Efficiency of PEMFC, battery and SC}

The efficiency of battery and SC primarily depends on the internal equivalent series resistance (ESR) of the energy storage devices. For SCs, their charge/discharge efficiency is high, and the energy lost to heat during operating procedure is relatively small and readily removed. But for batteries, their energy lost to heat is a much larger amount, making heat removal more crucial and its extraction cost is much higher. Consequently, the charging efficiency of batteries is more than around $80 \%$, as shown in Fig. 10, and the charging efficiency of SCs is around 95\%, that it is easy to calculate. For instance, the energy stored and consumed for the SC in this mode is

$$
E_{S C}=\frac{1}{2} C\left(V_{\text {cha.min }}^{2}-V_{\text {cha.max }}^{2}\right)=\frac{1}{2} C\left(V_{\text {dis.max }}^{2}-V_{\text {dis.min }}^{2}\right)
$$

As mentioned above, because $V_{\text {cha. } \min }=V_{\text {disc } \min }=30 \mathrm{~V}, V_{\text {cha } \max }=V_{\text {disc. } \max }=41 \mathrm{~V}$, and $C=N_{C}^{p} \frac{C_{\text {cell }}}{N_{C}^{s}}=2 \times \frac{120 F}{16}=15 \mathrm{~F}$, we can calculate that $E_{S C}=5,857.5 \mathrm{~J}$. 


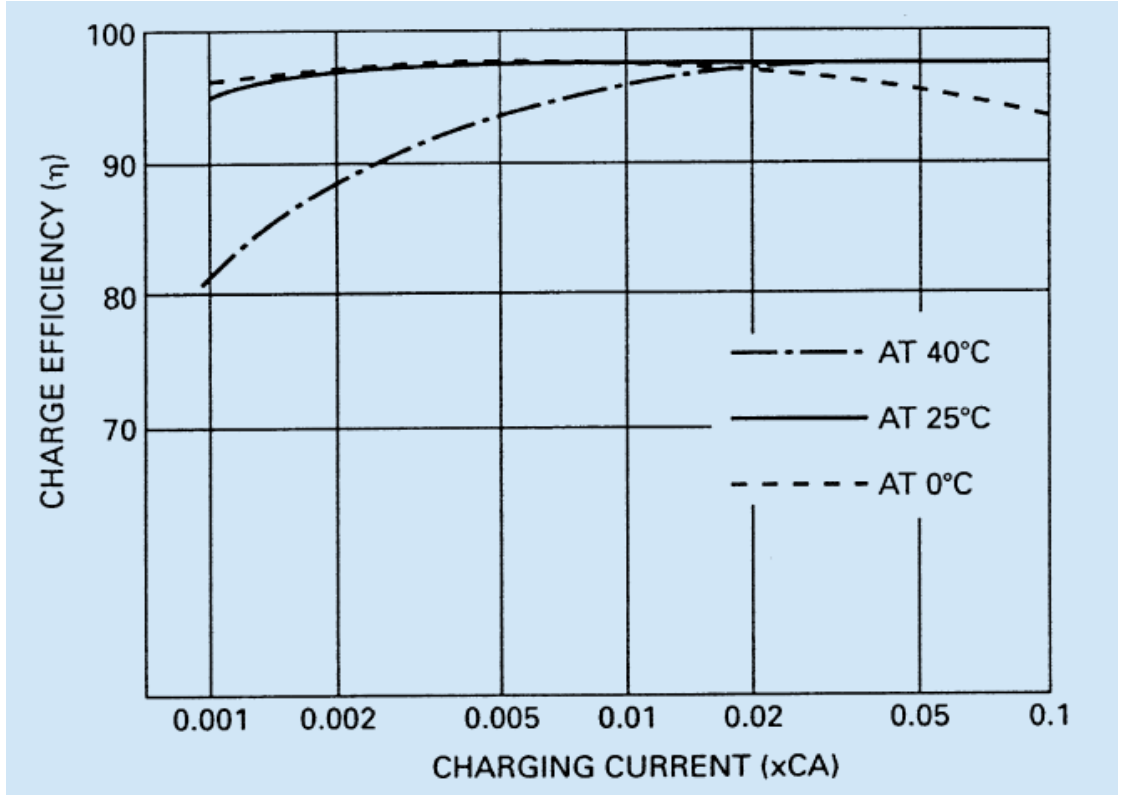

Fig. 10. Battery efficiency employed in the UPS system [17]

According to the charging characteristics of SCs as shown in Fig. 11, the energy output of $\mathrm{AC} / \mathrm{DC}$ recharger is

$$
E_{\text {Out }}=V_{\text {Out }} \times I_{\text {Out }} \times t \cong(0.91 \times 36.3+0.9 \times 39.2+0.89 \times 41) \times 60 \mathrm{~s}=6288(\mathrm{~J})
$$

Therefore, its efficiency is

$$
\eta_{S C}=\frac{E_{S C}}{E_{\text {out }}} \times 100 \%=\frac{5857.5}{6288} \times 100 \%=93.2 \%
$$

Furthermore, the main drawback of batteries is a slow charging time, limited by a charging current. In contrast, SCs may be charged over a short time, depending on a high charging current and power that is available from the main source [18]. 


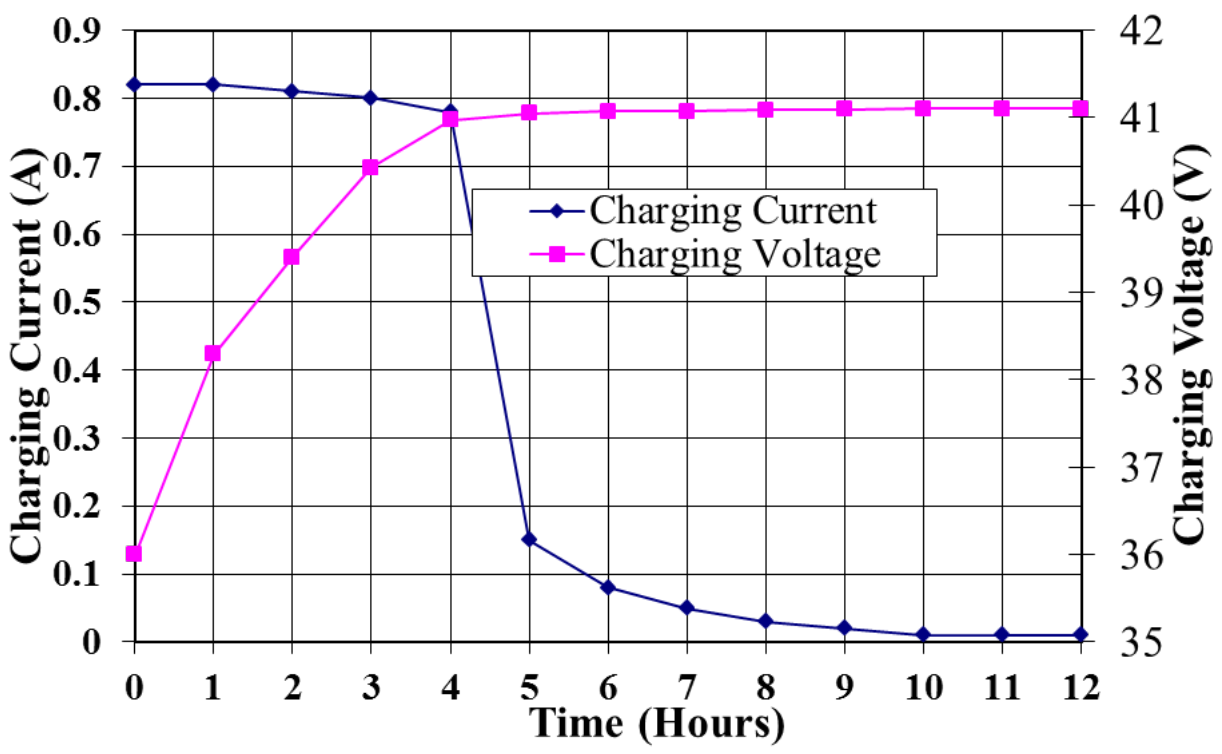

Fig. 11. Charging characteristics of SCs in this UPS system

The PEMFC efficiency is shown in Fig. 12, where the PEMFC efficiency is about $45 \%$ under the rated load of 270W, which is less than that of battery and SC, but higher than that of gasoline engine (less than 35\%).

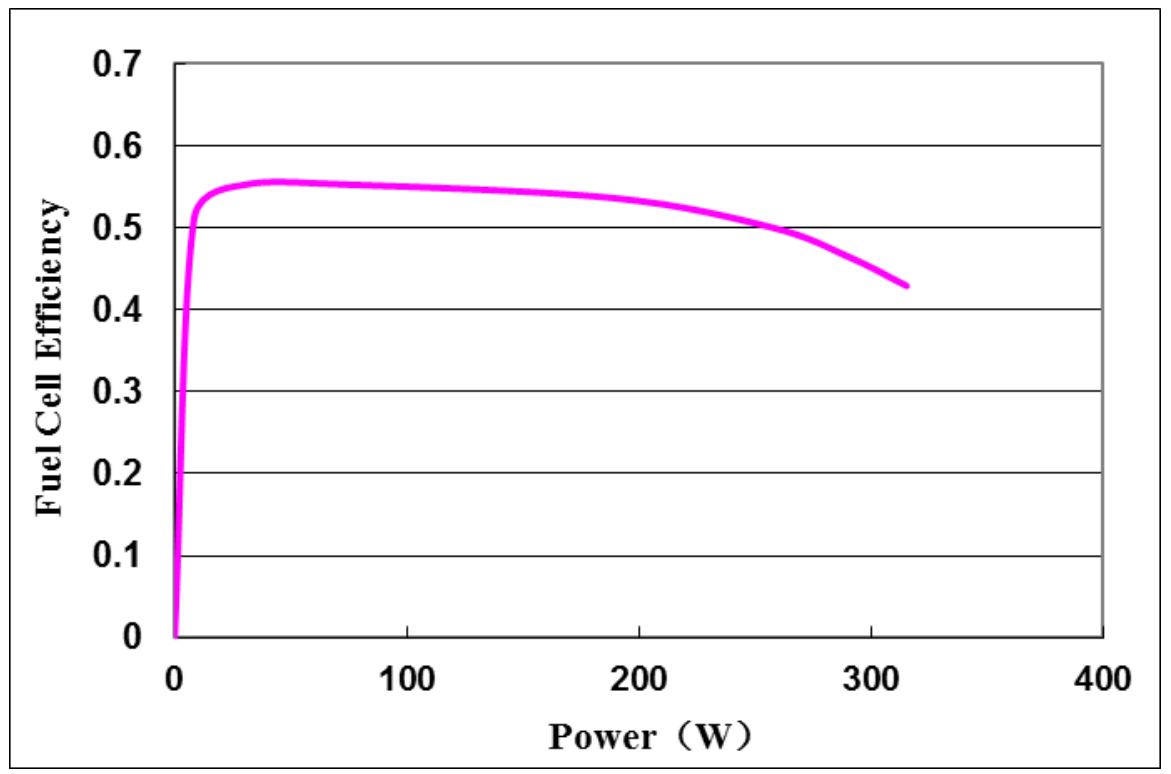

Fig. 12. PEMFC efficiency employed in the UPS system

\subsubsection{Charging of battery and SC}


A basic switch power system with universal input voltage and adjustable output voltage is designed as the battery charger based on a high-performance current mode PWM controller UC3845, which is almost constant-current and constant-voltage charging circuit. When the utility grid power fails and the PEMFC supplies the UPS hybrid system in the normal mode, the PEMFC can also charge the battery if the battery voltage is less than the rated value, but the PEMFC cannot release the charging of the constant current and constant voltage (41V/1A) for lead-acid battery, unless a DC/DC converter is designed to charge the battery through the PEMFC, or the system efficiency will be affected. On the other hand, when charging and discharging a battery, not all the energy is delivered into and from the battery due to battery losses, which are characterized by the battery efficiency. Fig. 13 shows the charging characteristics of the battery under the conditions of the depth of discharge of $100 \%$ and the temperature of $25^{\circ} \mathrm{C}$, when the power control and energy management control unit turns on $\mathrm{K}_{4}$ [19].

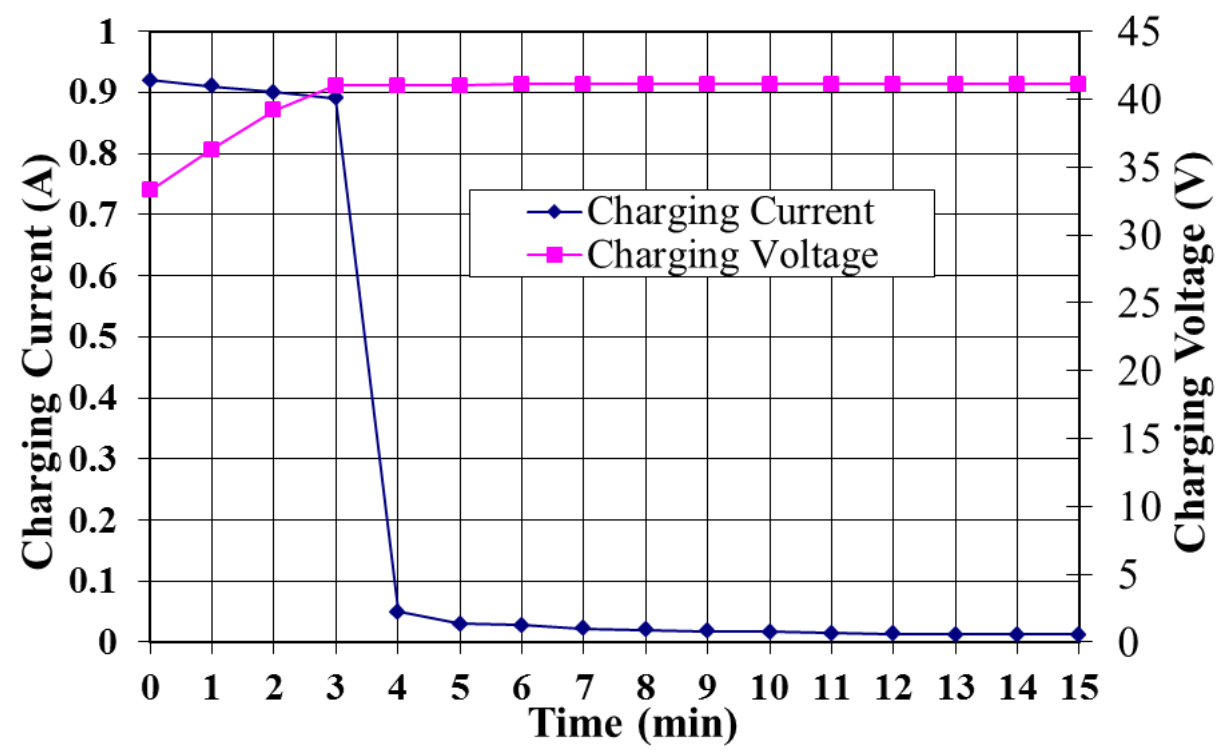

Fig. 13. Charging characteristics of battery in UPS system

A SC behaves like a very high-power and low-capacity battery but stores electric energy by accumulating and separating opposite charges physically, as opposed to batteries, which store energy chemically in reversible chemical reactions. Two methods can be 
employed to charge the SC in the system. One is the same as the method to charge the battery, and Fig. 12 shows the charging characteristics under the conditions of the constant current and constant voltage when the power control and energy management control unit turns on K6. The other is to charge the SCs by the FC as depicted in Fig. 16, when the power control and energy management control unit turns on $\mathrm{K} 2$ and $\mathrm{K} 3$, the PEMFC can directly charge the SCs. If the initial voltage of SCs is less than $30 \mathrm{~V}$, a higher current will be caused and shot the PEMFC down. But the power control and energy management unit can start the FC again, as shown in Fig. 14. To prevent the PEMFC shutting down when charging, the power control and energy management control unit firstly turns on K3 and K4, which lets the battery charge the SCs, and then turns on K2 and K4, which lets the PEMFC charge the SCs. Fig. 14 are the voltages and currents of the PEMFC and SCs when FC charges SCs and the SC initial voltage is less than $20 \mathrm{~V}$.

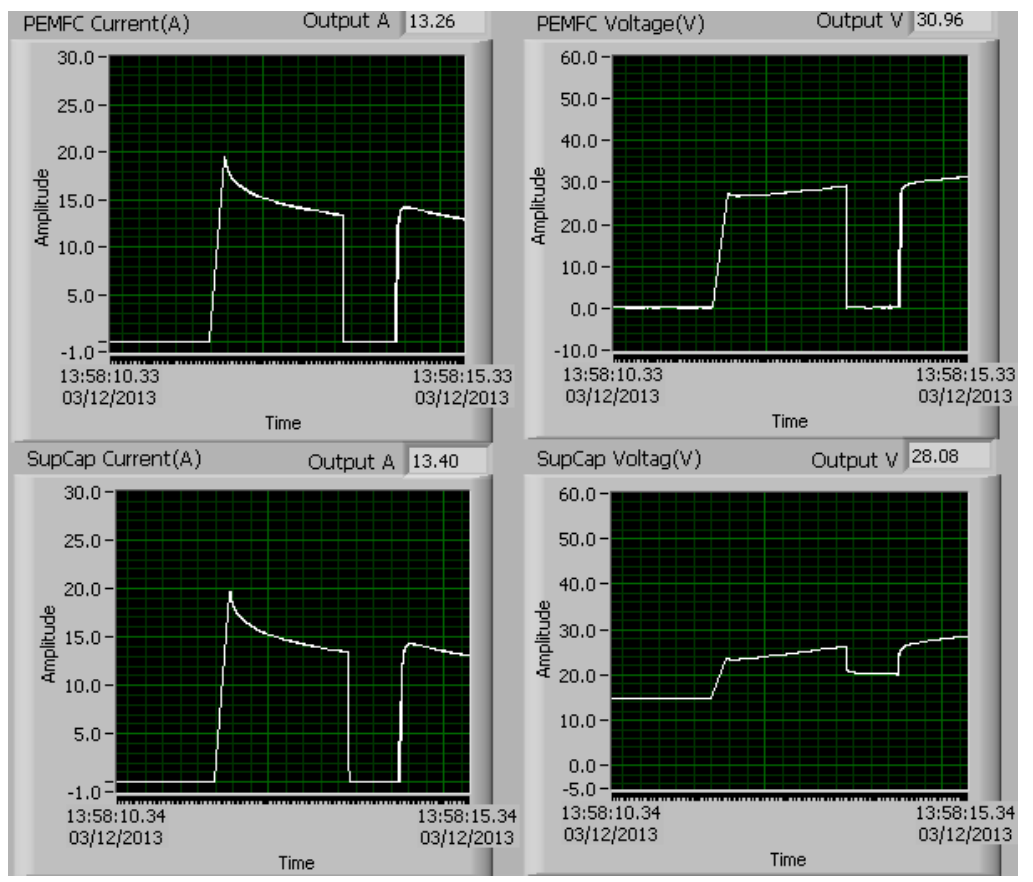

Fig. 14. Voltages and currents waveform of PEMFC and SCs when FC charges SCs if SC voltage is less than $20 \mathrm{~V}$

When the utility grid is used to charge the battery, the input power of grid measured 
is $P_{\text {Grid }}=I V=0.436 \mathrm{~A} \times 241.6 \mathrm{~V}=105.3 \mathrm{~W}$, and the input power of battery measured is $P_{\text {Bat }}=I V=0.84 \mathrm{~A} \times 35.8 \mathrm{~V}=29.9 \mathrm{~W}$, hence, the efficiency of AC/DC recharger is $\eta_{U P S(B a t . C h a)}=\eta_{A C / D C(r c)}=28.4 \%$.

When the utility grid is used to charge the SC, the input power of grid measured is $P_{\text {Grid }}=I V=0.321 \mathrm{~A} \times 242.1 \mathrm{~V}=77.7 \mathrm{~W}$, and the input power of battery measured is $P_{\text {Bat }}=I V=0.92 \mathrm{~A} \times 33.3 \mathrm{~V}=30.6 \mathrm{~W}$, consequently, the efficiency of AC/DC recharger is $\eta_{U P S(S C . C h a)}=\eta_{A C / D C(r c)}=39.4 \%$.

\subsubsection{Discharging of SC and battery}

The discharging dynamics of battery and SC are dependent on the dynamics of their equivalent circuits, which have a finite charge capacity $Q_{\max }$, and their open circuit voltages are dependent on their current charge state $Q$.

\subsubsection{Discharging of SC}

Discharging of a SC is a simple example of electrochemical energy storage device. According to equation (14), the discharging current is

$$
I=-\frac{d Q}{d t}=-C \frac{d V_{C}}{d t}
$$

The voltage applied to the external resistance is

$$
V=\frac{Q}{V_{C}}-I R_{\text {cell }}=I R_{\text {load }}
$$

Suppose the total resistance $R=R_{\text {cell }}+R_{\text {load }}$, the discharging time $T_{C}^{s}$ equals approximately the decay time $\tau=R C$.

Fig. 15 shows the discharging process diagrams of two 16-cell SCs in parallel when the 
main PEMFC fails. The load of UPS is at the rated power of $270 \mathrm{~W}$, and the minimum SC discharging voltage is $30 \mathrm{~V}$. The discharging time is about $13 \mathrm{~s}$ (starting time: 10:26:34.04, ending time: 10:26:47.35, which does not meet the demand of theoretical design of 15 s. Because the measured efficiency of UPS in this mode is $75 \%$, the discharging current is

$$
I=\frac{P}{V_{\min } \eta}=\frac{270}{30 \times 0.75}=12(A)
$$

On the other hand, the balance of the SCs used in series is a main issue, that is, some cell voltages of them are less than $2.7 \mathrm{~V}$ after charged. The discharging time is less than 15 s (designed value).

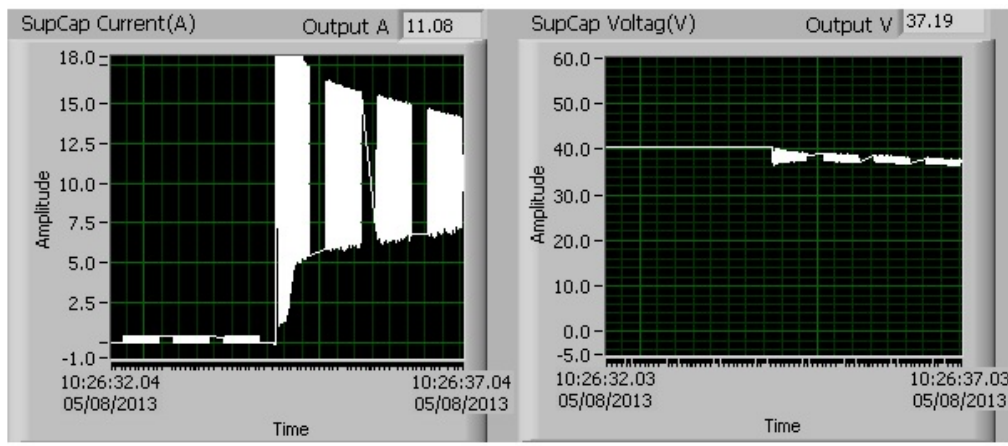

(a) Dischaging of SC Starts up

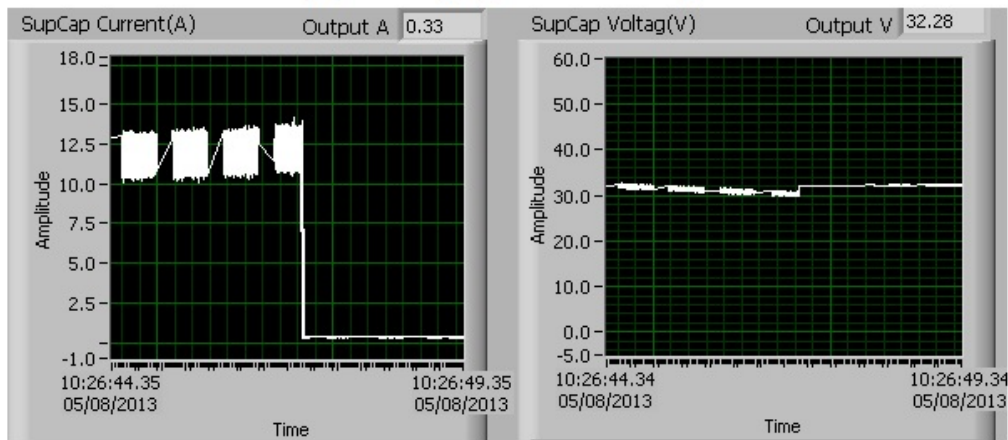

(b) Discgarging of SC ends

Fig. 15. Voltages and currents waveform of SC discharging when the main PEMFC fails

\subsubsection{Discharging of battery}

Because the open circuit voltage of lead-acid battery is a function of charge and the current, a simple equivalent circuit for a battery can thus be written as

$$
V=V_{0}(Q)-V(I, Q)=I R_{\text {load }}
$$


where $V_{0}(Q)$ is the open circuit voltage when $I=0 ; V(I, Q)$ the cell overpotential (relative to the equilibrium), which is a positive voltage loss for a positive (galvanic) current $I>0$, and negative for a negative (electrolytic) current $I<0$. This model assumes that the voltage depends only on the instantaneous current and state of charge, and not on the prior history.

For the nonlinear electrical response of a battery, the different common modes of discharge are constant current, constant load, and constant power. In the UPS system, discharge of battery can occur at a constant power. The voltage will drop off even faster than that at constant current, since the current must be increased with time to compensate for the decreasing voltage and maintain constant power, which is

$$
P=I V=\text { Cons } \tan t
$$

Substituting (18) into (19), we have

$$
P=\left[V_{0}(Q)-V\left(\frac{d Q}{d t}, Q\right)\right]\left(\frac{d Q}{d t}\right)
$$

This is a first-order nonlinear ordinary differential equations (ODE). It can be solved by first obtaining $d Q / d t$ as a function of $Q(t)$, which is a first order separable ODE. Considering again a battery with open circuit voltage, which is

$$
V(t)=V_{0}\left[1-\left(\frac{Q}{Q_{\max }}\right)^{2}\right],
$$

and neglecting the internal resistance, then integrating equation (20), an implicit solution for $Q(t)$ can be obtained as

$$
P=V_{0} Q_{\max }\left[\frac{Q}{Q_{\max }}-\frac{1}{3}\left(\frac{Q}{Q_{\max }}\right)^{3}\right]
$$

Fig. 16 shows the discharging process diagrams of 3-cell lead-acid batteries when the main PEMFC fails, while the load of UPS is the rated power of $270 \mathrm{~W}$ and the minimum discharging voltage is $30 \mathrm{~V}$. The discharging time is $17 \mathrm{~min}$ and $15 \mathrm{~s}$ (starting time: 
10:38:30.75, ending time: 10:55:45.75 ), which meets the demand of theoretical design.

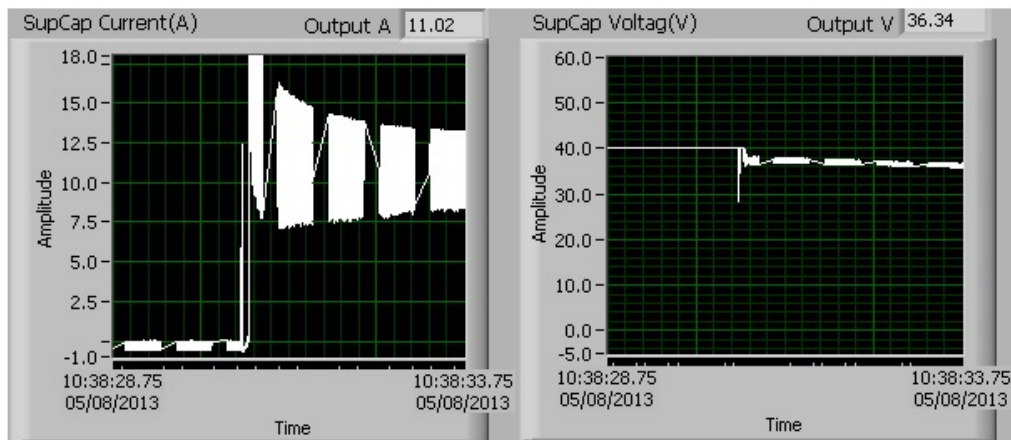

(a) Battery discharging starts up

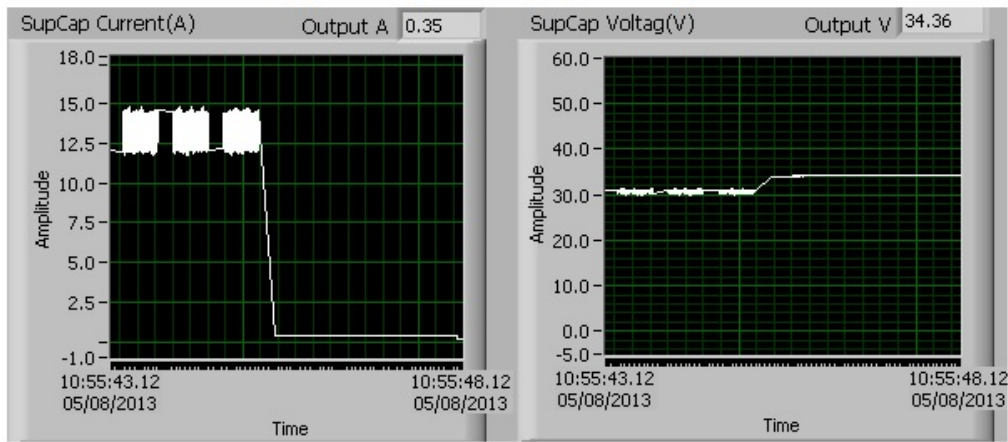

(b) battery discharging ends

Fig. 16. Voltages and currents waveform of battery discharging when main PEMFC fails

\section{Experimental Setup and Validation}

\subsection{Experimental setup}

The experimental setup consists of a UPS hybrid power sources system and an intelligent power control and energy management controller, 3-cell deep cycle lead-acid batteries, two 16-cell 120F/2.7V of SCs, a 300W self-humidified air-breathing of PEMFC generating system and the data-acquisition devices including multifunction analog input unit PCI-6036E, analog output unit PCI-6713, parallel digital I/O interface PCI-6503 and analog multiplexer with temperature sensor AMUX-64T (National Instruments). The UPS hybrid system with backup PEMFC and SC/battery provides the AC power source and controls the linear loads (e.g. lamp box and resistances) and nonlinear loads (i.e. PC), while the data-acquisition system measures and records the required information. In the PEMFC generating and testing system, both hydrogen and air are regulated by two mass flow controllers (type: F-201C-GAS-22V and F-112AC-GAS-22V, Bronkhorst). The 
temperature and humidity of air and hydrogen can be measured at the inlet by the hydrotransmitter (type: HD2008TV1, Delta OHM) as well as the pressure transmitter (type: AUS EX 1354X, Burkert) between the inlets of cathode and anode. The output of the UPS is connected to a lamp load that is used in a constant power mode. All physical parameters such as currents and voltages of the UPS hybrid system, the PEMFC stacks, SC and battery, the gas mass flow of the hydrogen, the pressure, relative humidity and temperatures of air and hydrogen are recorded with the data-acquisition devices. Fig. 17 shows a photo of the experimental setup.

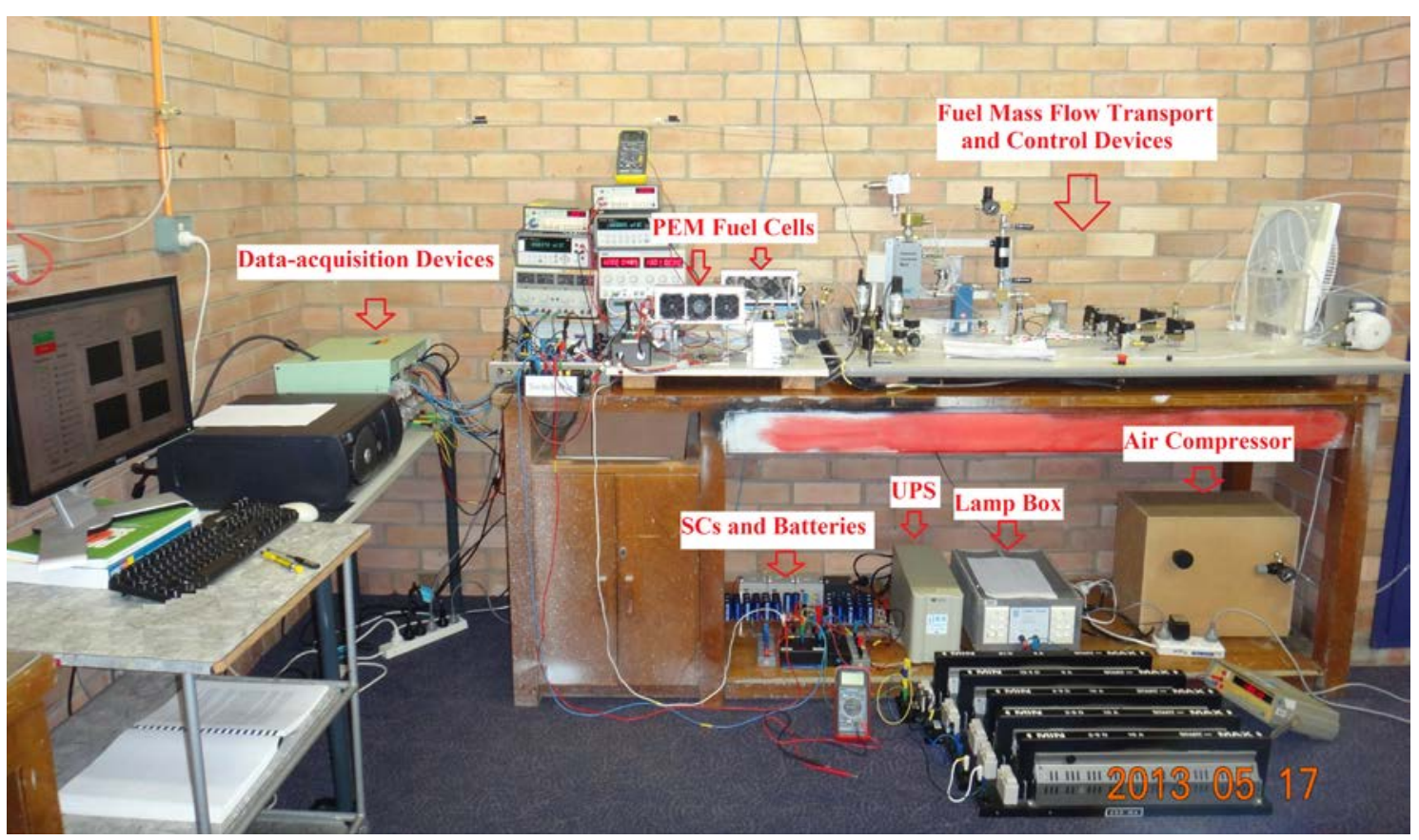

Fig. 17. Photo of the experimental setup

\subsection{Experimental validation}

The experimental test and analysis have been carried out on the PEMFC generating system and intelligent network UPS hybrid system. As mentioned and discussed above, the performances of the four operating modes of UPS hybrid system are measured with the load of a lamp box.

\subsubsection{Utility grid operating mode}

Based on the developed intelligent UPS system, the voltage-current and power-current 
performances of the UPS are tested under the conditions of the grid operating mode. Fig. 18 shows the measured power, current curves of input and output and the efficiency profile for UPS without charging the battery and SC.
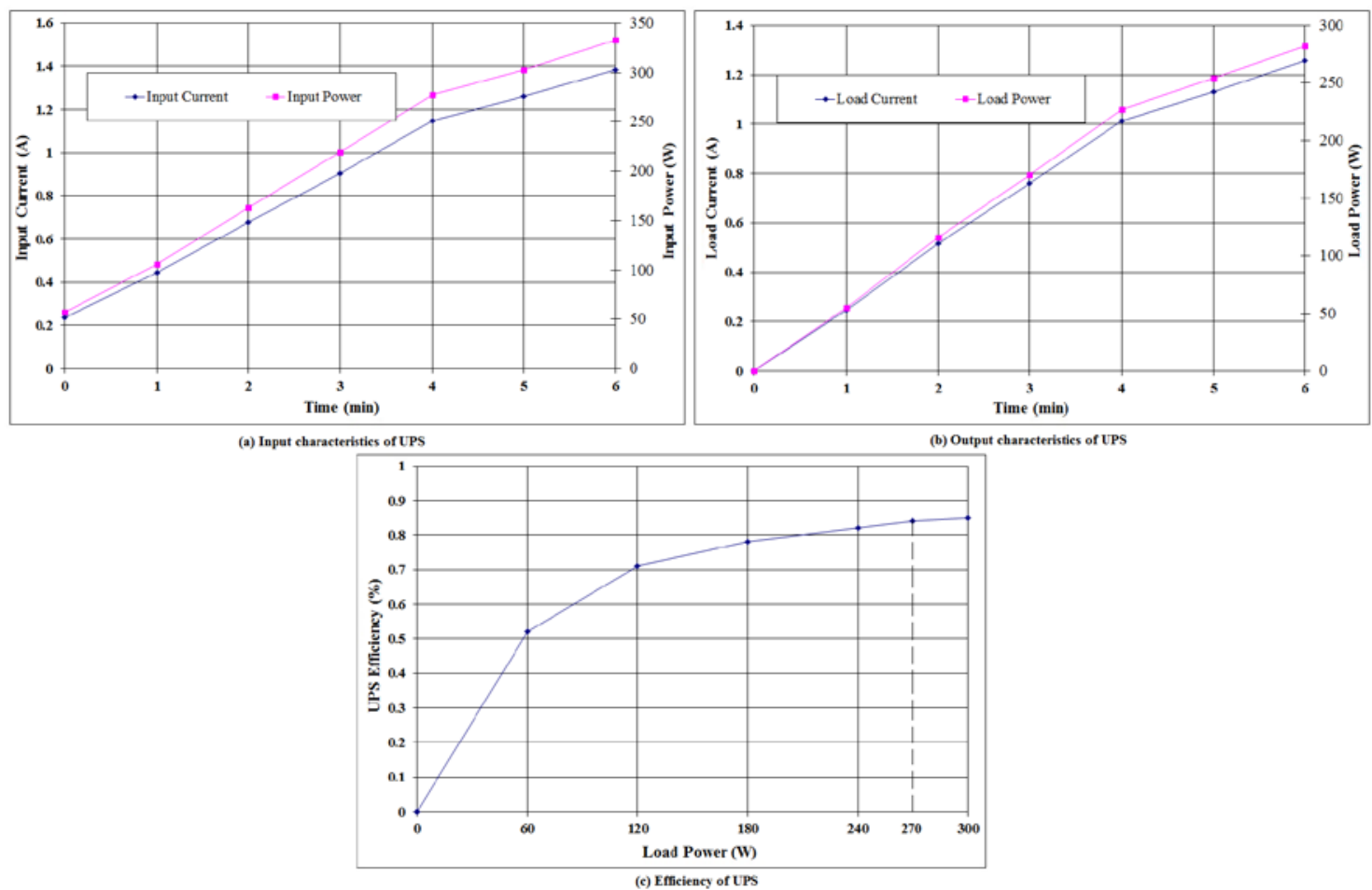

Fig. 18. Power, current and efficiency characteristics of UPS under the grid operating mode

According to the measured value, the efficiency of UPS under the rated load of 270W is

$$
\eta_{\mathrm{UPS}(\mathrm{Grid})}=\eta_{A C / D C(\mathrm{rt})} \eta_{D C / A C}=85 \%
$$

In grid operating mode, for a high frequency UPS system, its efficiency in the utility grid operating mode should be more than $90 \%$ under the rated load of $270 \mathrm{~W}$. Nevertheless, it is $85 \%$, because the rated capacity of UPS designed is a $1000 \mathrm{VA} / 700 \mathrm{~W}$ system.

\subsubsection{Bypass operating mode}

Fig. 19 shows the measured power, current curves of input and output and the efficiency profile for UPS without charging the battery and SC. 

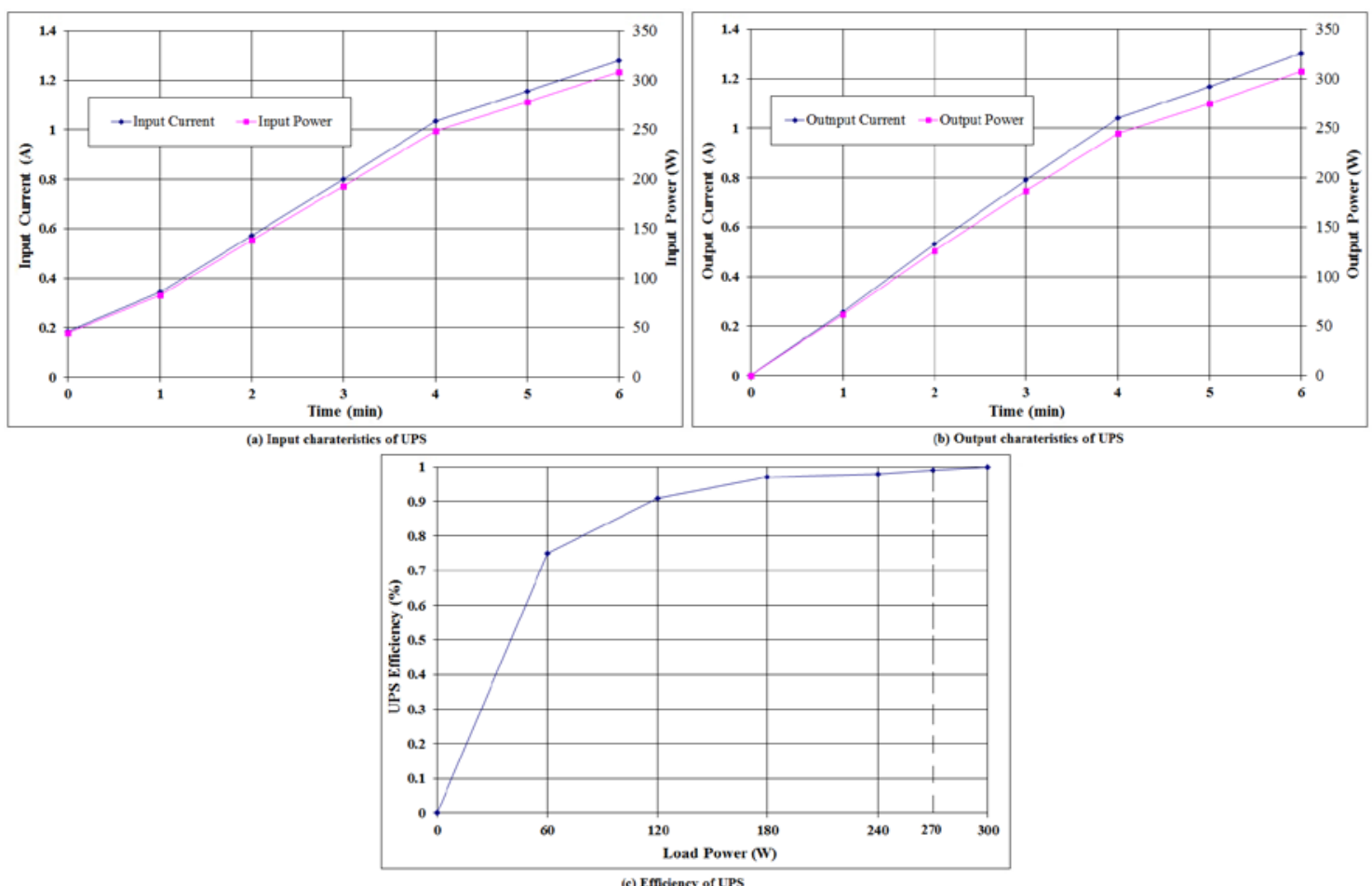

Fig. 19. Power, current and efficiency characteristics of UPS under the bypass operating mode

According to the measured value, the efficiency of UPS in the bypass operating mode under the rated load of $270 \mathrm{~W}$ is

$$
\eta_{U P S(\text { Bypass })}=98 \%
$$

In the bypass operating mode, because the energy flows through the thyristor $\mathrm{K}_{0}$ and wire, the UPS has a loss of $2 \%$.

\subsubsection{Battery operating mode}

Fig. 20 shows the measured input power and current curves of the battery and the output and the efficiency profile for UPS. 

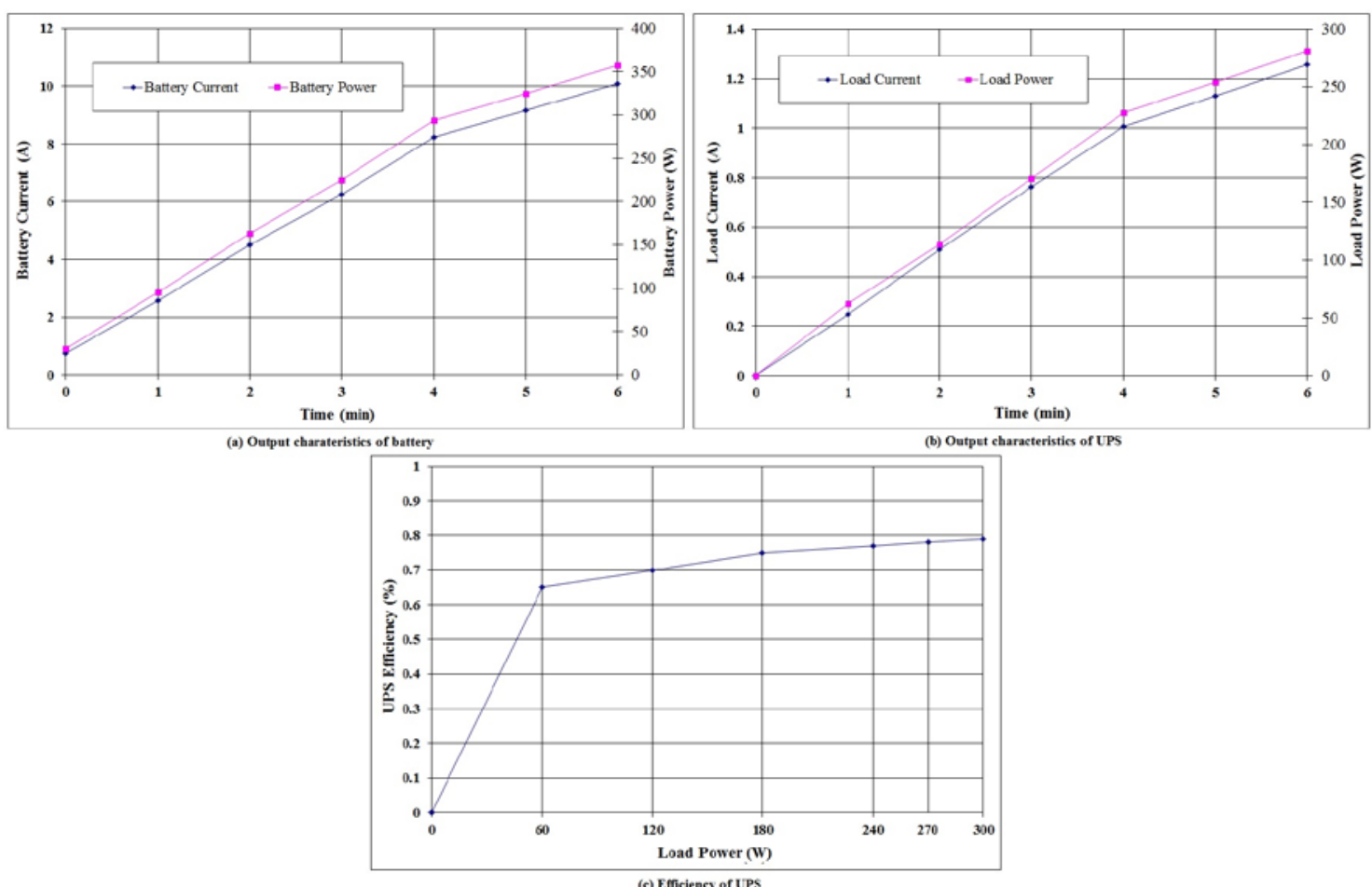

Fig. 20. Power, current and efficiency characteristics of battery and UPS under the battery operating

mode

According to the measured value, the efficiency of UPS under the rated load of 270W is

$$
\eta_{\mathrm{UPS}(\mathrm{Bat})}=\eta_{D C / D C} \eta_{D C / A C}=78 \%
$$

In battery operating mode, because $\eta_{\mathrm{DC} / \mathrm{DC}}$ is less than $\eta_{\mathrm{AC} / \mathrm{DC}(\mathrm{rt})}, \eta_{\mathrm{UPS}(\mathrm{Bat})}$ is less than $\eta_{\mathrm{UPS}(\text { Grid) }} \cdot$

\subsubsection{FC operating mode}

Fig. 21 shows the measured input power and current curves of the PEMFC and the output and the efficiency profile for UPS without charging the battery and SC. 

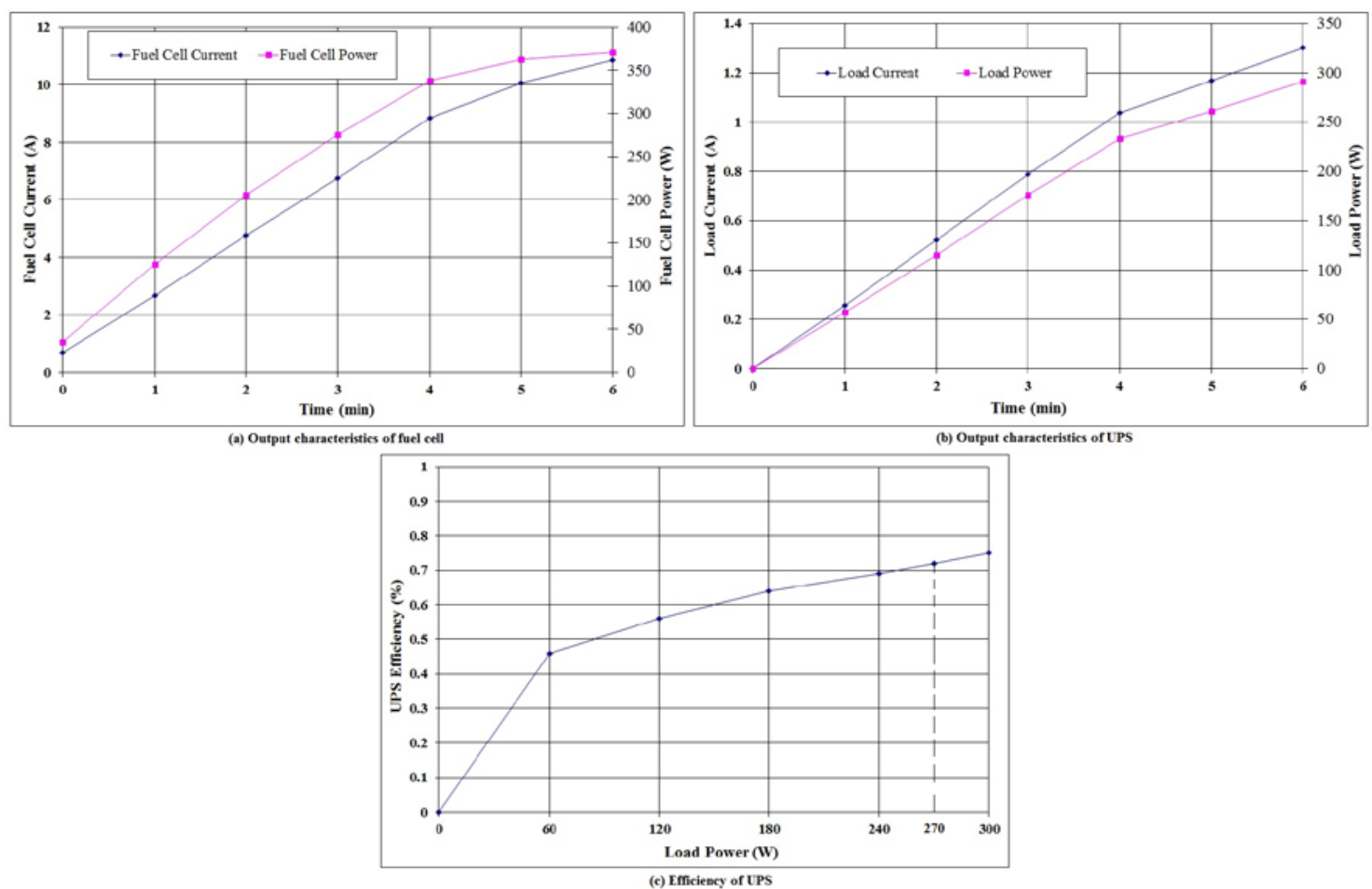

Fig. 21. Power, current and efficiency characteristics of PEMFC and UPS under the FC operating

mode

According to the measured value, the efficiency of UPS in FC operating mode under the rated load of $270 \mathrm{~W}$ is

$$
\eta_{\mathrm{UPS}(\mathrm{FC})}=\eta_{D C / D C} \eta_{D C / A C}=72 \%
$$

In FC operating mode, as a result of using the current interrupting method to measure the resistance of membrane and improve the performance of the PEMFC, a part of energy has to be lost, $\eta_{\mathrm{UPS}(\mathrm{FC})}$ is less than $\eta_{\mathrm{UPS}(\mathrm{Bat})}$. If the current interrupting does not be applied in this mode, $\eta_{\mathrm{UPS}(\mathrm{FC})}$ is almost the same as $\eta_{\mathrm{UPS}(\mathrm{Bat})}$.

Fig. 22 shows the voltages and currents waveform in the PEMFC operating mode, where the current interrupting method is used. 


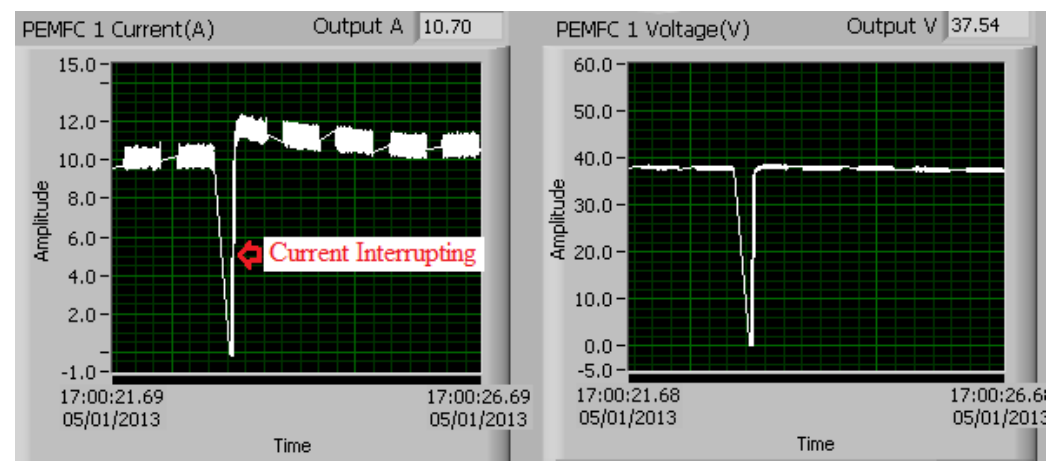

Fig. 22. Voltages and currents waveform of PEMFC operating mode when using the current interrupting

\subsubsection{SC operating mode}

Fig. 23 shows the measured input power and current curves of the SC and the output and the efficiency profile for UPS.
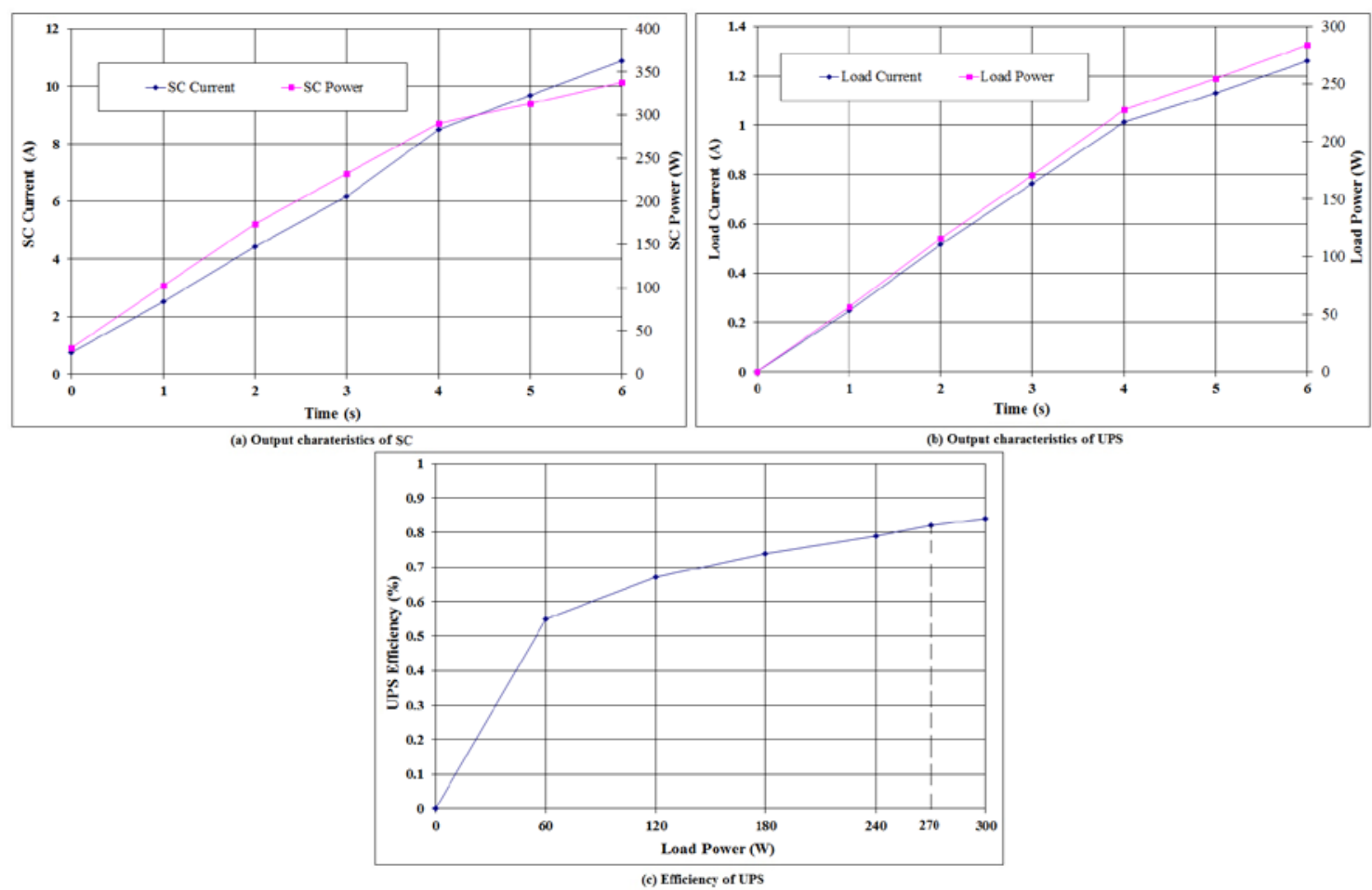

Fig. 23. Power, current and efficiency characteristics of SC and UPS under the SC operating mode

According to the measured value, the efficiency of UPS under the rated load of $270 \mathrm{~W}$ is 


$$
\eta_{\mathrm{UPS}(\mathrm{SC})}=\eta_{D C / D C} \eta_{D C / A C}=82 \%
$$

In SC operating mode, because $\eta_{\mathrm{UPS}(\mathrm{SC})}$ is more than $\eta_{\mathrm{UPS}(\mathrm{Bat})}$ or $\eta_{\mathrm{UPS}(\mathrm{FC})}$, it indicates that the SC has better performance in UPS applications, as compared with the PEMFC or battery.

In sum, the efficiency of the hybrid PEMFC/battery/SC power sources in the UPS applications is that the efficiency of the PEMFC is less than those of the battery and SC, and the efficiency of SC is the highest. And the total efficiency in UPS system needs deeply to improve. The results can be the same as that in the automobile applications.

\section{Conclusion}

The power control and energy management strategies and efficiency considerations of four operating modes for an intelligent network UPS system with backup PEMFC, SC and battery power sources are proposed in this paper, to overcome the slow dynamics when PEMFC starts up or an external load changes suddenly leading to the fuel starvation and degradation of the stack. Based on the designed UPS hybrid system, three stages of theoretical analysis and experimental test are conducted. Firstly, the modeling and the power sizing of PEMFC, SC and battery are presented and calculated. Then the proposed intelligent power control and energy management strategy of hybrid UPS system are implemented and examined. Finally, the experimental validation of the UPS hybrid system is tested. To realize the intelligent power and energy management strategies of the hybrid UPS system, the data acquisition system and PEMFC generating system using LabVIEW and UPS power control and energy management unit are employed and implemented. The theoretical analyses and experimental validations indicate that the developed power and energy management strategies in the UPS system with back PEMFC/SC/battery power sources are suitable for portable, backup and emergency power, and vehicles applications, and can guide the optimal design of the UPS system with hybrid PEMFC/battery/SC power sources. 


\section{References}

[1] FC TECHNOLOGIES PROGRAM, FY 2013 Budget Request Rollout to Stakeholders of U. S. Department of Energy, [online], http://www1.eere.energy.gov/hydrogenandfuelcells/pdfs/fy13_budget_request_rol lout.pdf

[2] US FCs: Multi-year Research, Development and Demonstration Plan, 2011 Executive Summary, [online], available at http: //www1.eere.energy.gov /hydrogenandfuelcells/mypp/pdfs/exec_sum.pdf

[3] 2011 Technical Plan - FCs of U.S. Department of Energy, [online], http://www1.eere.energy.gov/hydrogenandfuelcells/mypp/pdfs/fuel_cells.pdf

[4] DOE Hydrogen and FC Overview, ASME 2011- Plenary, 5th International Conference on Energy Sustainability, Washington, DC, August 8, 2011, http://www1.eere.energy.gov/hydrogenandfuelcells/pdfs/asme_aug2011_plenary_ overview.pdf

[5] Thounthong P, Chunkag V, Sethakul P, Davat, B, Hinaje M. Comparative study of fuel-cell vehicle hybridization with battery or SC storage device. IEEE Trans on Vehicular Technology 2009; 58(8):3892-904.

[6] Thounthong P, Rael, Davat B. Energy management of FC/battery/SC hybrid power source for vehicle applications. J Power Sources 2009; 193(1):376-85.

[7] Zhang WP, Xu DH, Li X, Xie R, Li HJ, Dong DZ, Sun C, Chen M. Seamless transfer control strategy for FC uninterruptible power supply system. IEEE Trans on Power Electronics 2013; 28(2):717-28.

[8] García P, Torreglosa JP, Fernandez LM, Jurado F. Control strategies for high-power electric vehicles powered by hydrogen FC, battery and SC. Expert Systems with Applications 2013; 40(12):4791-804.

[9] Torreglosa JP, García P, Fernández LM, Jurado F. Predictive control for the energy management of a FC-battery-SC tramway. IEEE Trans on Industrial Informatics 2014; 10(1):276-85. 
[10] Kyriakarakos G, Dounis AI, Arvanitis KG, Papadakis G. A fuzzy logic energy management system for polygeneration microgrids. Renewable Energy 2012; 41:315-27.

[11] Kyriakarakos G, Piromalis DD, Dounis AI, Arvanitis KG, Papadakis G. Intelligent demand side energy management system for autonomous polygeneration microgrids. Applied Energy 2013; 103:39-51.

[12] Feroldi D, Degliuomini LN, Basualdo M. Energy management of a hybrid system based on wind-solar power sources and bioethanol. Chemical Engineering Research and Design 2013; 91(8):1440-55.

[13] Zhan YD, Wang H,Zhu JG. Modelling and control of hybrid UPS system with backup PEMFC/battery. Int J Electrical Power \& Energy Systems 2012; 43(1):1322-31.

[14] Barbir F. FEM FC: Theory and Practice. Elsevier Academic Press, New York; 2005 [chapter 2].

[15] Faranda R. A new parameters identification procedure for simplified double layer capacitor two-branch model. Electric Power Systems Research 2010; 80(4):363-71.

[16] Mierlo JV, Bossche PV, Maggetto G. Models of energy sources for EV and HEV: FCs, batteries, ultracapacitors, flywheels and engine-generators. J Power Sources 2004; 128 (1): 76-89.

[17] Yuasa Battery Sales Ltd., NP Valve Regulated Lead Acid Battery Manual, 1999 [chapter 4].

[18] Burke AF. Batteries and Ultracapacitors for Electric, Hybrid, and FC Vehicles. Proceedings of the IEEE 2007; 95(4):806-20.

[19] Zhan YD, Guo YG, Zhu JG, Wang H. Intelligent uninterruptible power supply system with back-up FC/battery hybrid power source. J Power Sources 2008; 179(2):745-53. 
Figure Captions:

1. Traditional structure of fuel cell/battery/SC hybrid power source

2. Proposed structure of grid/fuel cell/battery/SC hybrid power source in UPS application

3. Equivalent circuit of a PEMFC

4. Boundary conditions for macroscopic potentials in an SC

5. Transmission line equivalent circuit model of an SC

6. Equivalent circuit of SC

7. Equivalent circuit of a lead-acid battery

8. Equivalent circuit of SCs in parallel and in series

9. Four operating modes of the proposed UPS system with grid/FC/battery/SC hybrid power sources

10. Battery efficiency employed in the UPS system [17]

11. Charging characteristics of SC in this UPS system

12. PEMFC efficiency employed in the UPS system

13. Charging characteristics of battery in UPS system

14. Voltages and currents waveform of PEMFC and SCs when FC charges SCs if SC voltage is less than $20 \mathrm{~V}$

15. Voltages and currents waveform of SC discharging when the main PEMFC fails 16. Voltages and currents waveform of battery discharging when main PEMFC fails 17. Photo of the experimental setup 
18. Power, current and efficiency characteristics of UPS under the grid operating mode

19. Power, current and efficiency characteristics of UPS under the bypass operating mode

20. Power, current and efficiency characteristics of battery and UPS under the battery operating mode

21. Power, current and efficiency characteristics of FC and UPS under the FC operating mode

22. Voltages and currents waveform of PEMFC operating mode when using the current interrupting

23. Power, current and efficiency characteristics of SC and UPS under the SC operating mode 


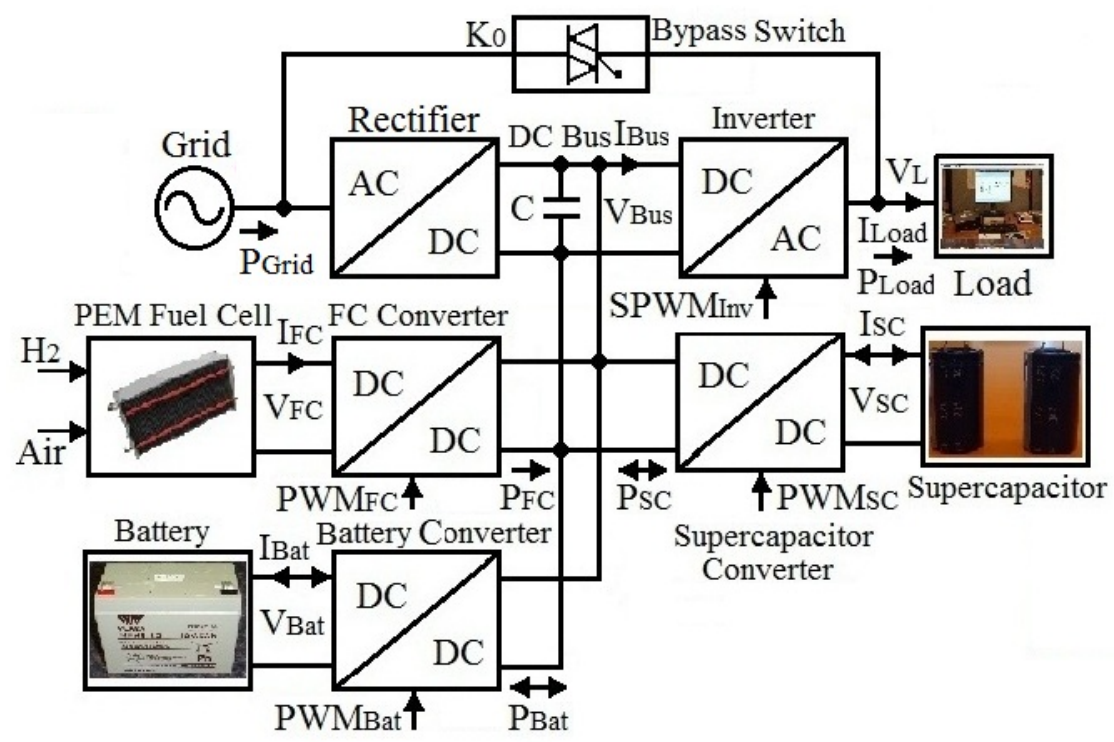

Fig. 1. Traditional structure of PEM fuel cell/battery/SC hybrid power source 


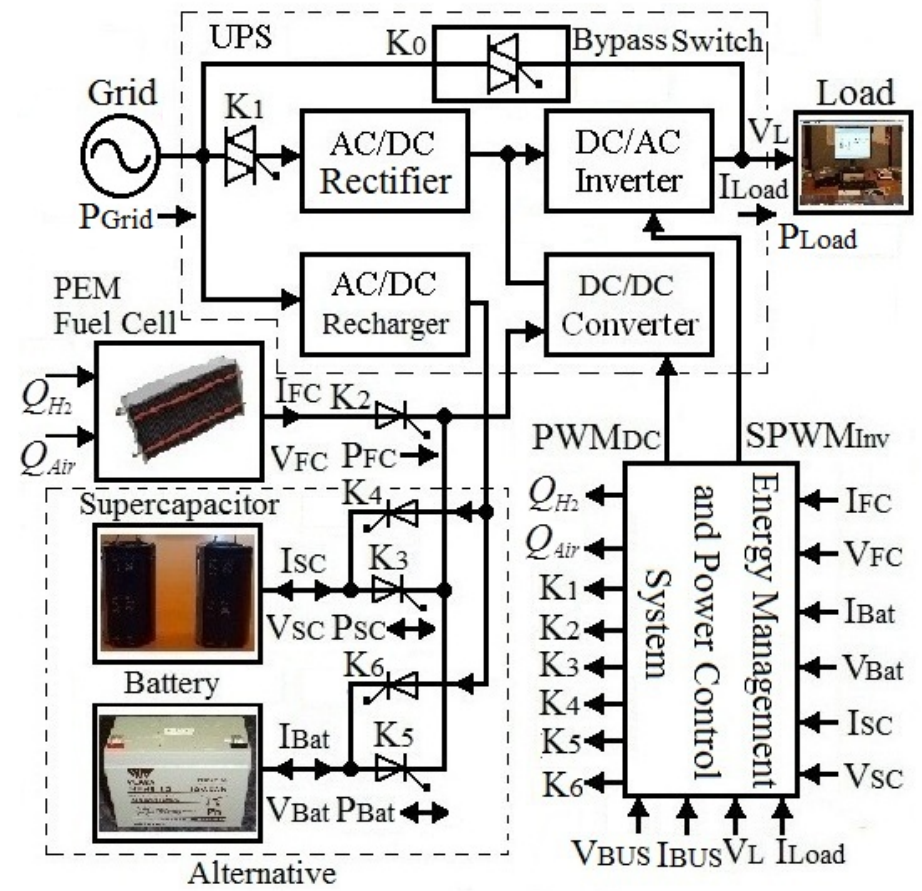

Fig. 2. Proposed structure of grid/fuel cell/battery/SC hybrid power source in UPS application 


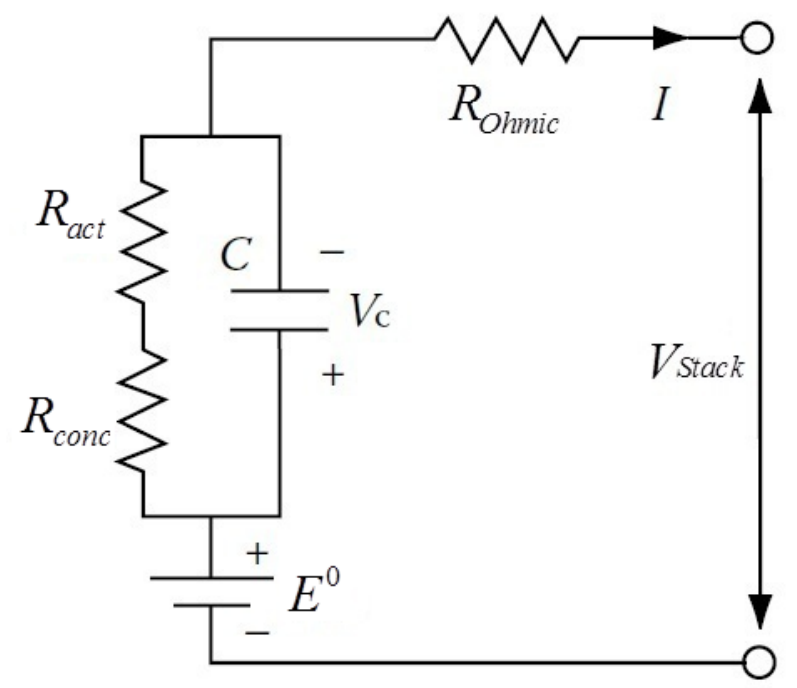

Fig. 3. Equivalent circuit of a PEMFC 


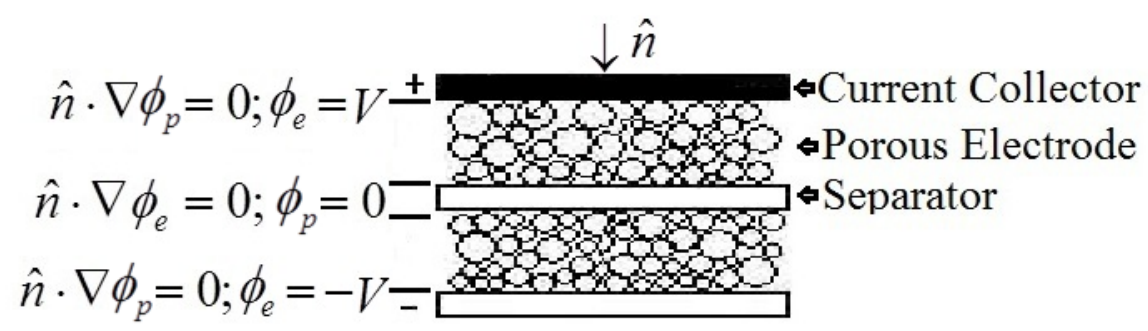

Fig. 4. Boundary conditions for macroscopic potentials in an SC 


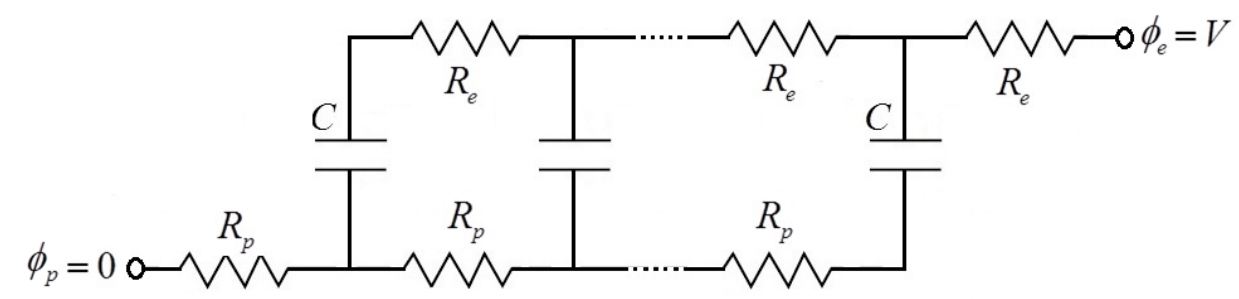

Fig. 5. Transmission line equivalent circuit model of an SC 


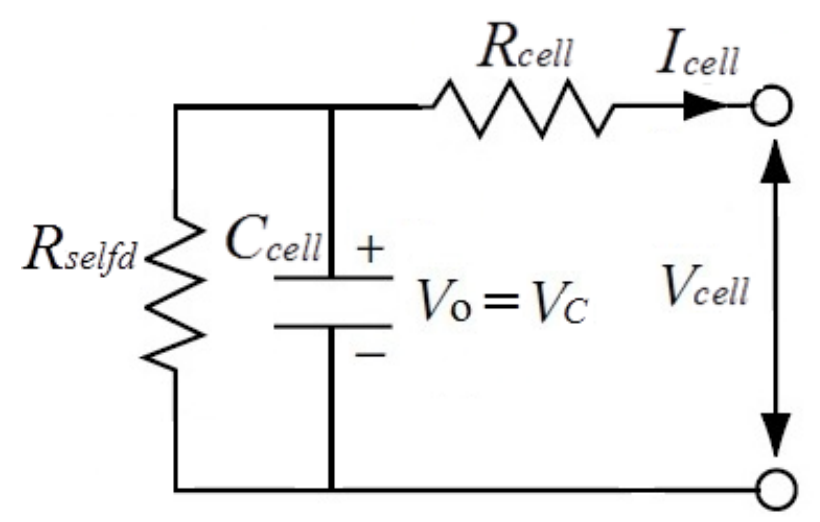

Fig. 6. Equivalent circuit of SC 


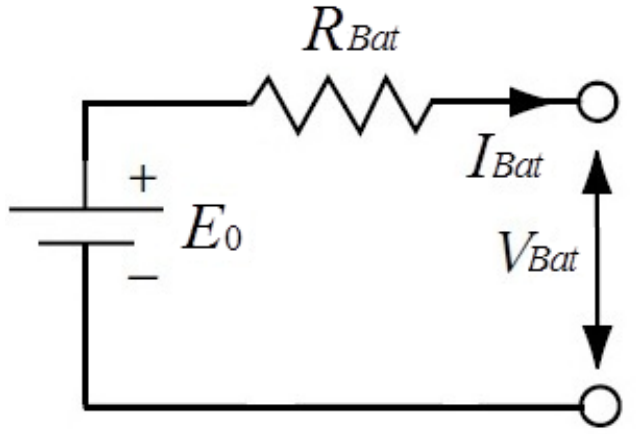

Fig. 7. Equivalent circuit of a lead-acid battery 


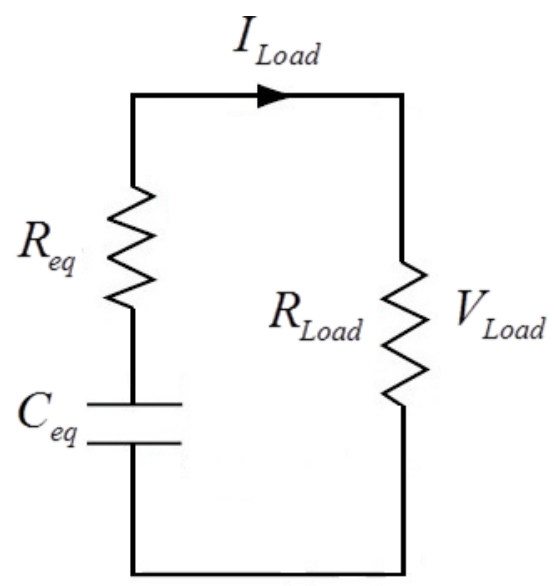

Fig. 8. Equivalent circuit of SCs in parallel and in series 


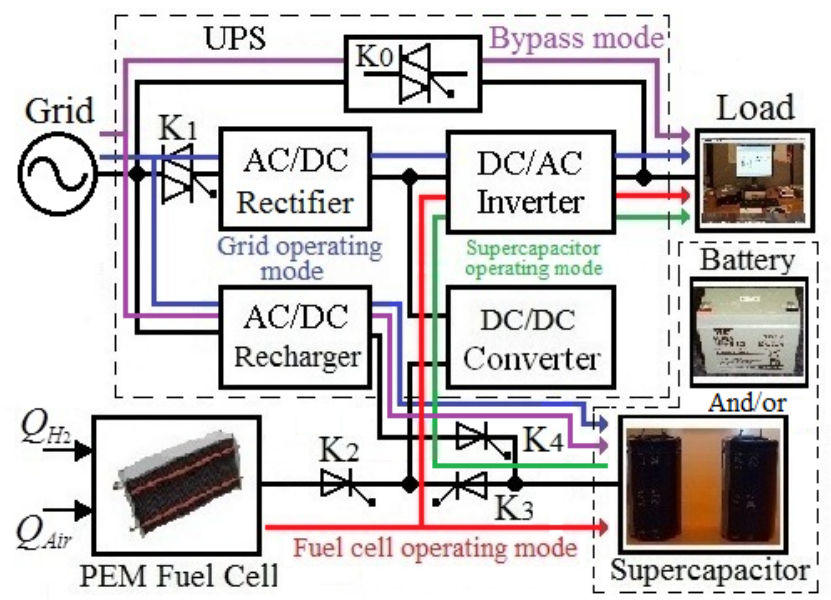

Fig. 9. Four operating modes of the proposed UPS system with grid/PEMFC/battery/SC hybrid power sources 


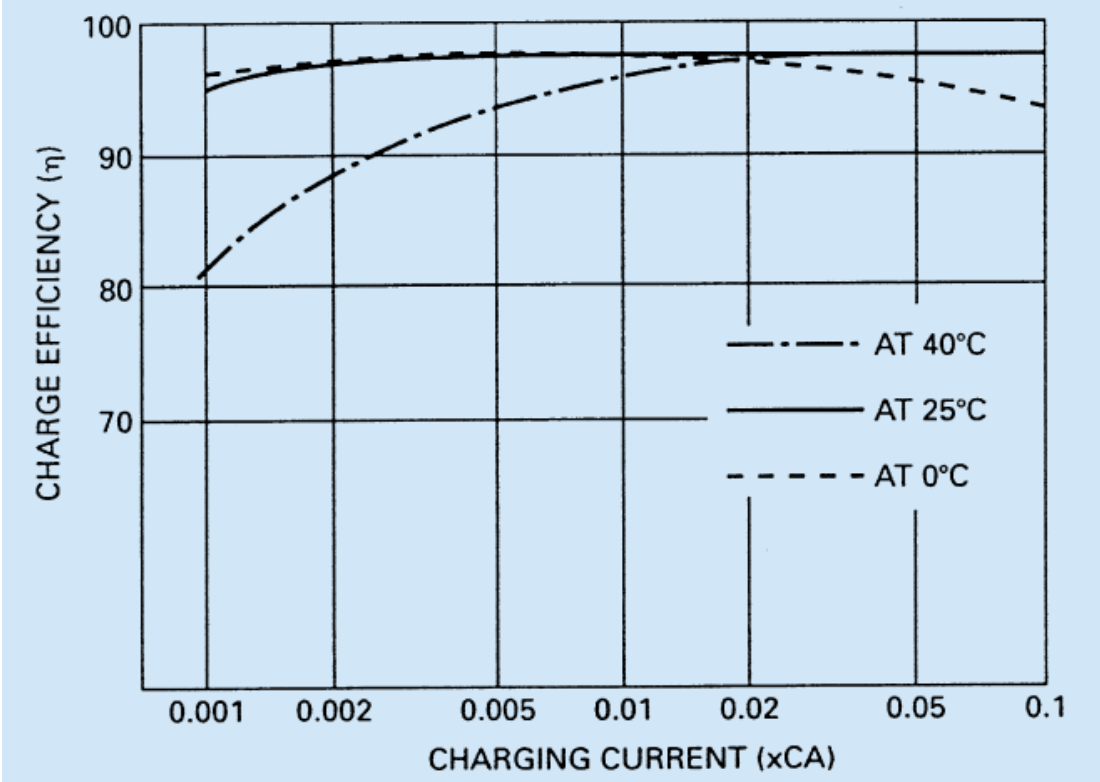

Fig. 10. Battery efficiency employed in the UPS system [17] 


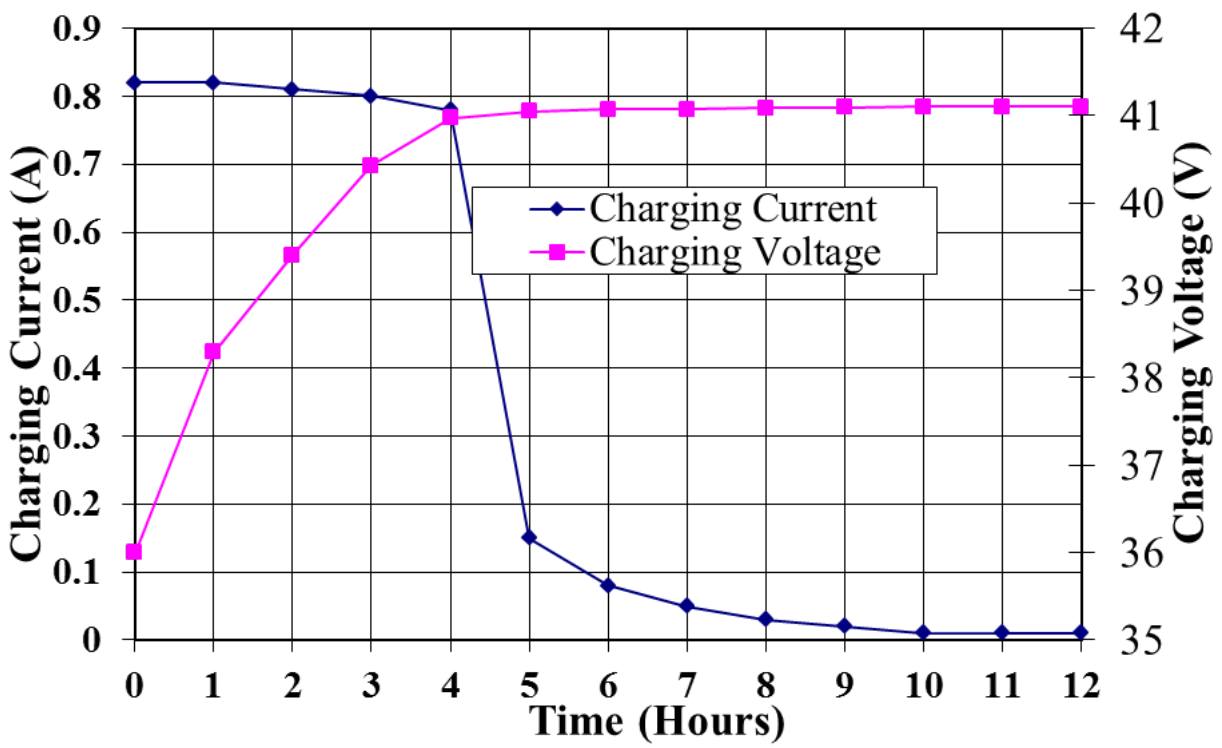

Fig. 11. Charging characteristics of SCs in this UPS system 


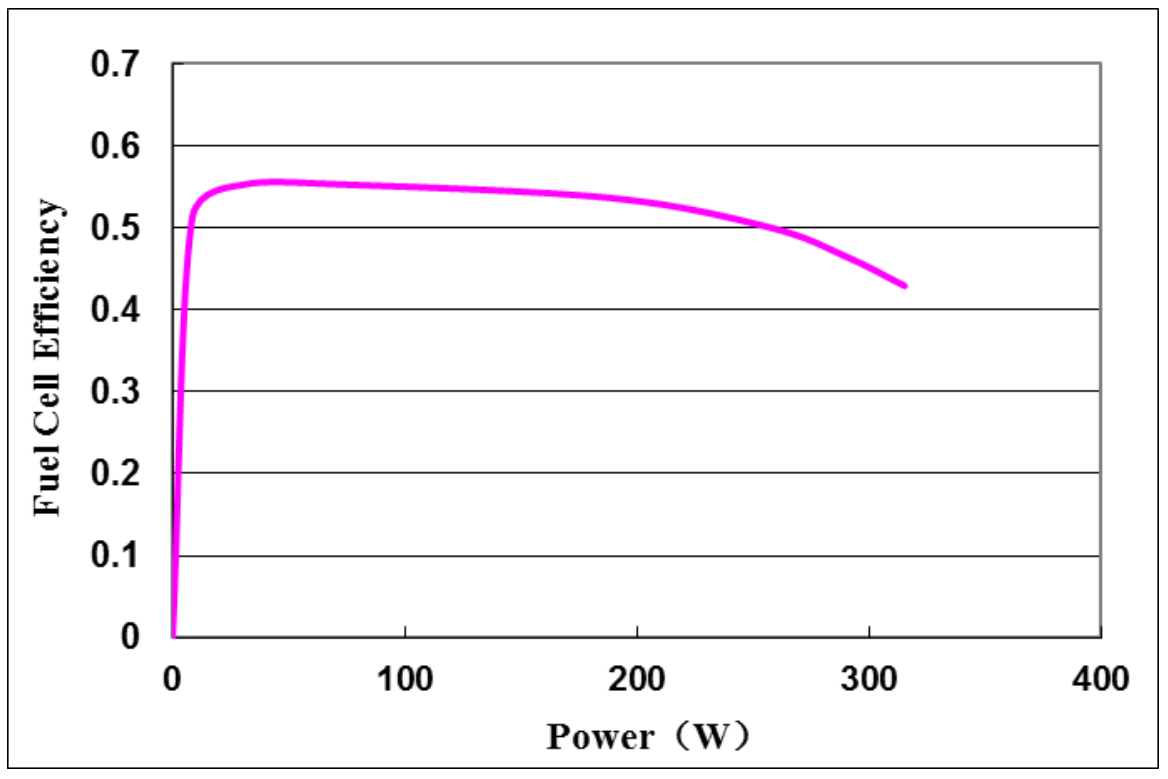

Fig. 12. PEMFC efficiency employed in the UPS system 


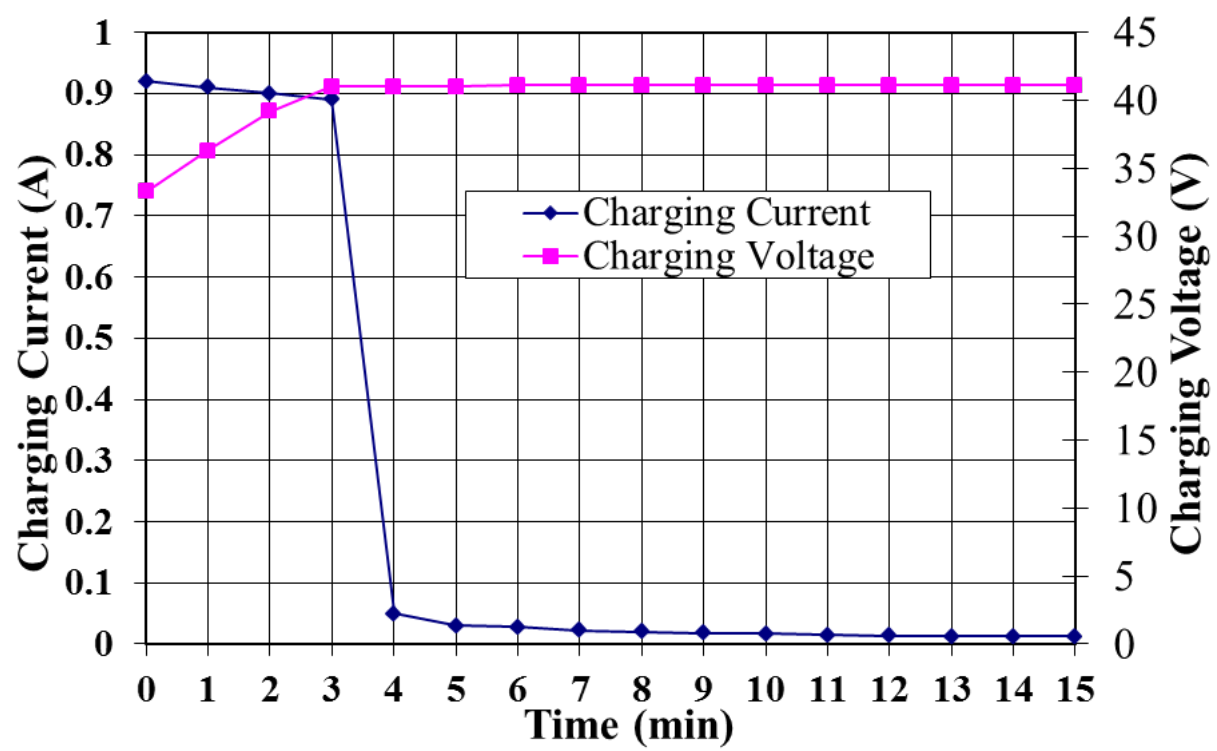

Fig. 13. Charging characteristics of battery in UPS system 


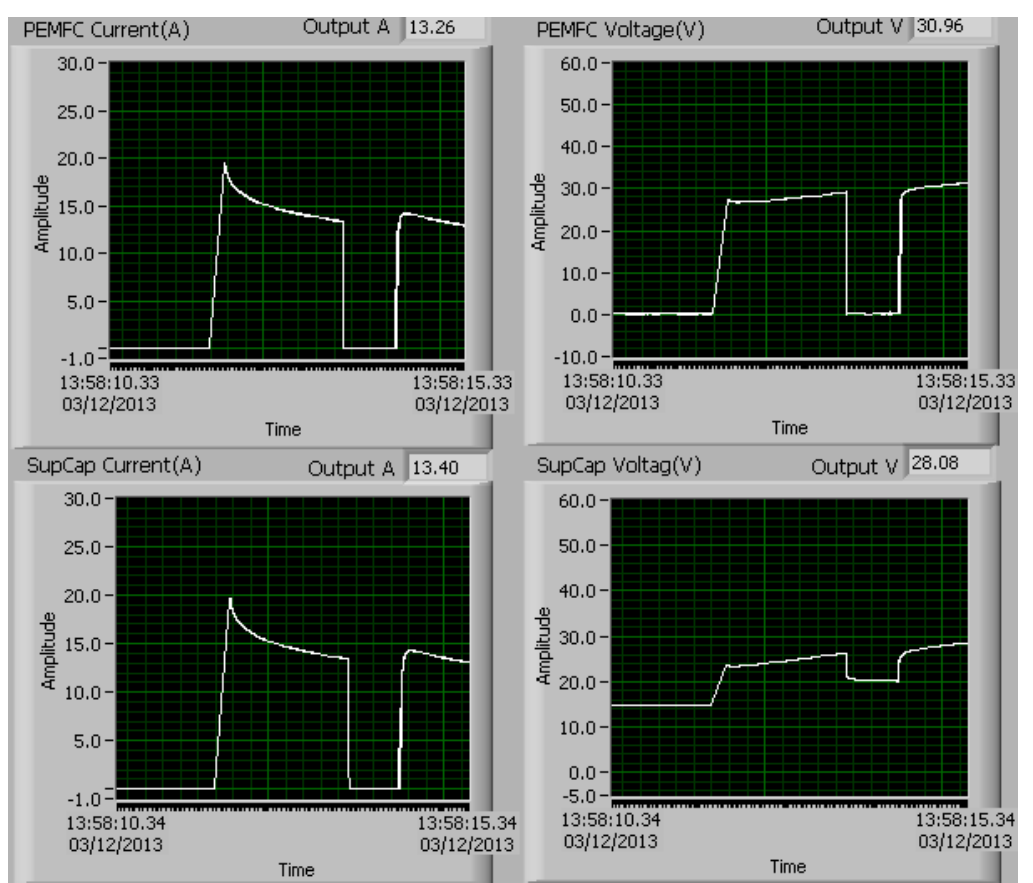

Fig. 14. Voltages and currents waveform of PEMFC and SCs when FC charges SCs if SC voltage is less than $20 \mathrm{~V}$ 


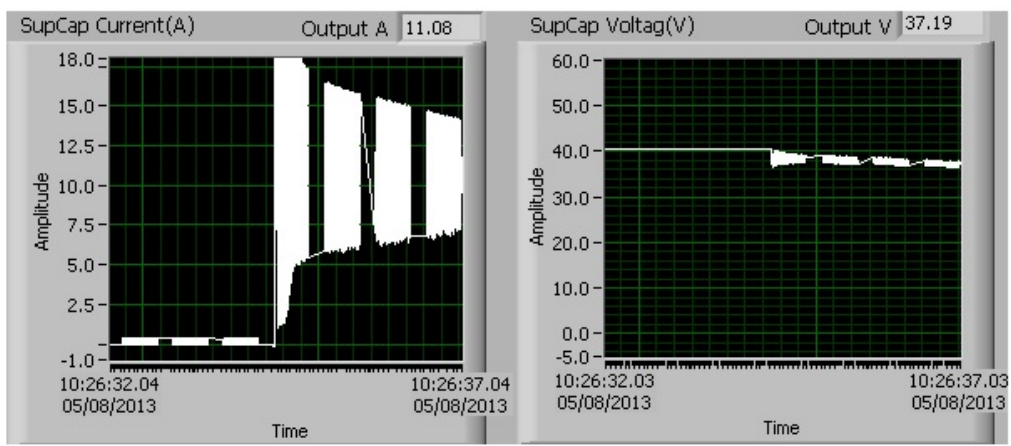

(a) Dischaging of SC Starts up

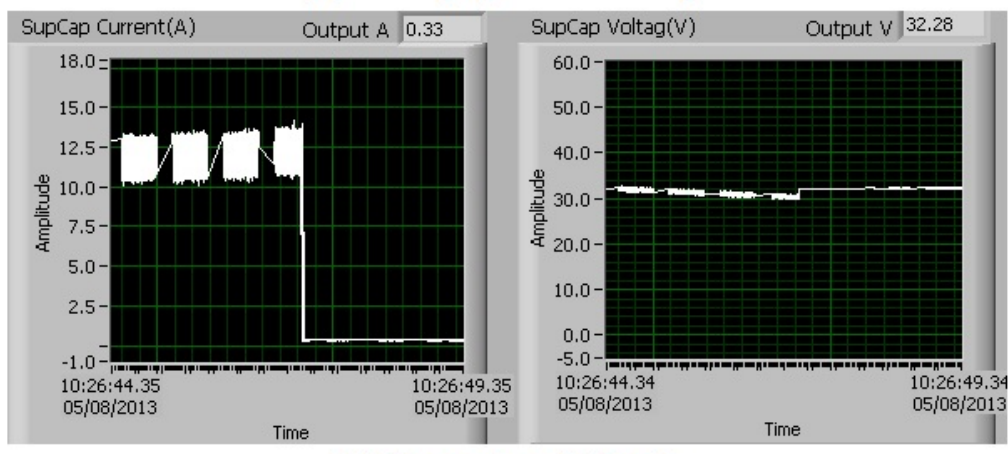

(b) Discgarging of SC ends

Fig. 15. Voltages and currents waveform of SC discharging when the main PEMFC fails 


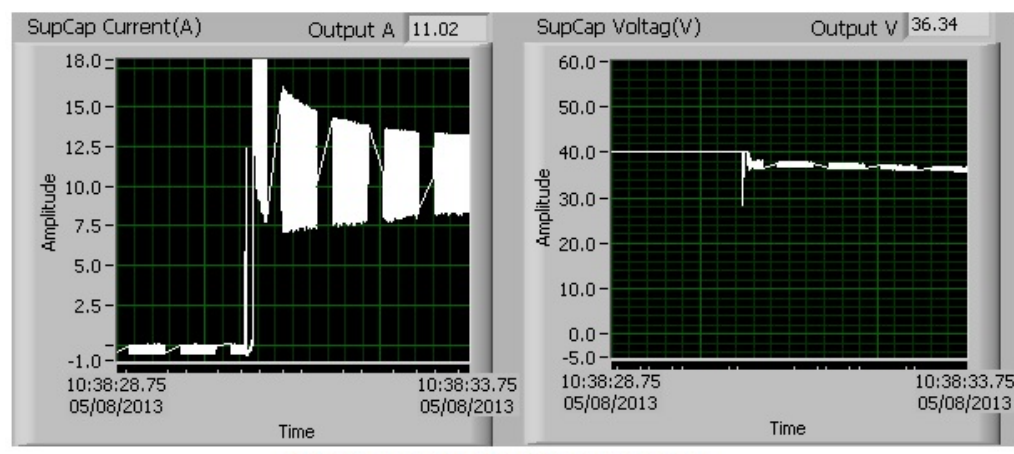

(a) Battery discharging starts up

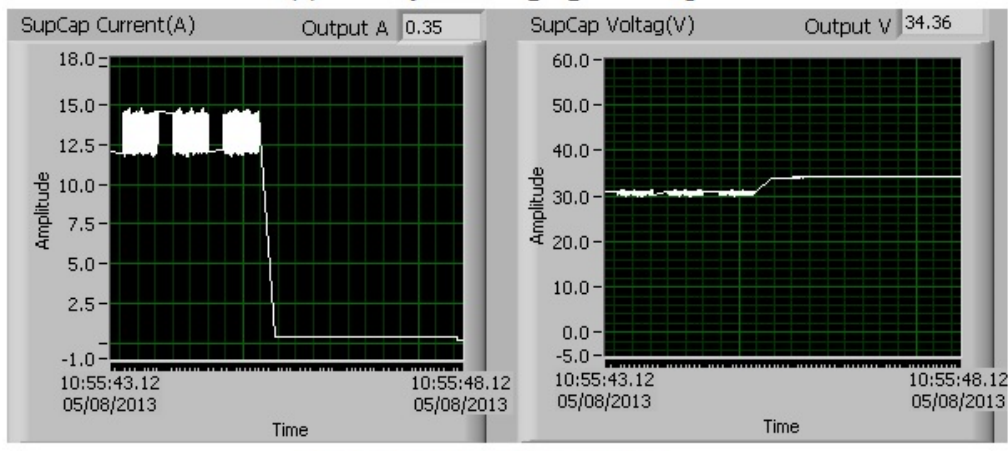

(b) battery discharging ends

Fig. 16. Voltages and currents waveform of battery discharging when main PEMFC fails 


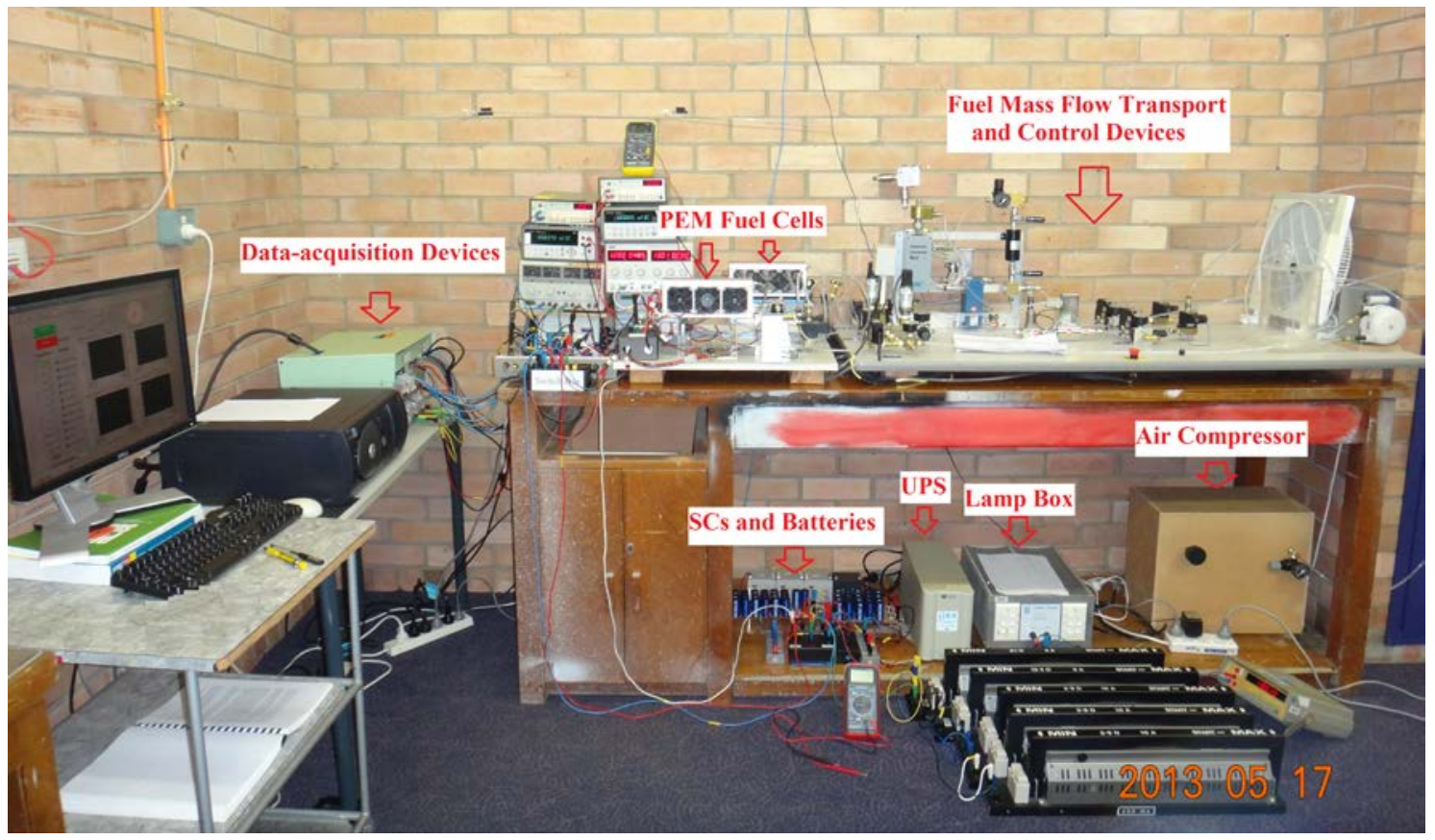

Fig. 17. Photo of the experimental setup 

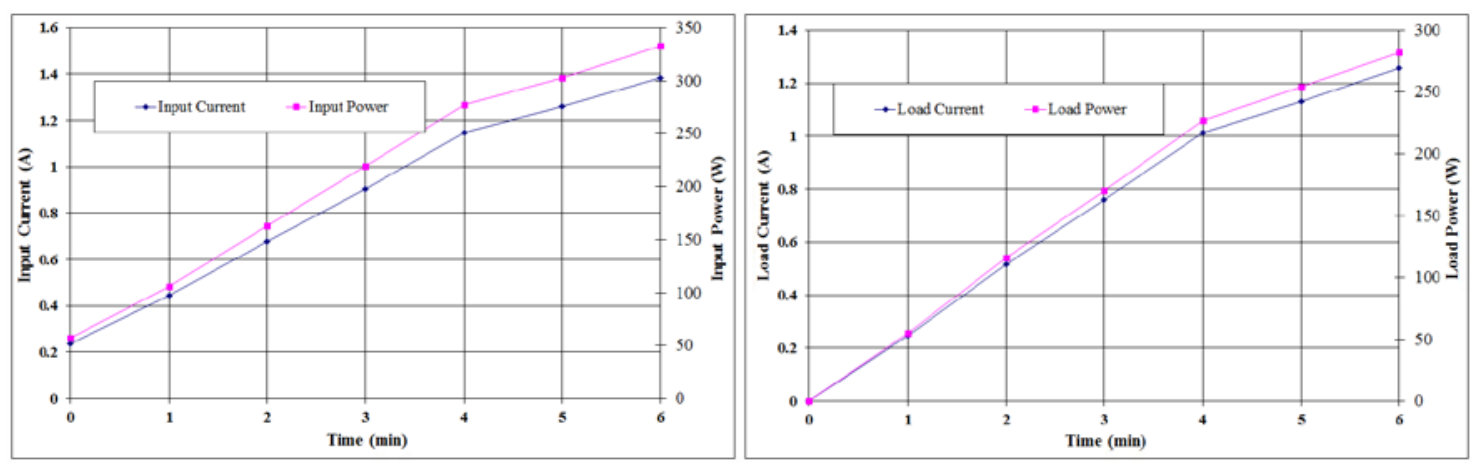

(a) Input characteristies of LPS

(b) Output characteristies of LPS

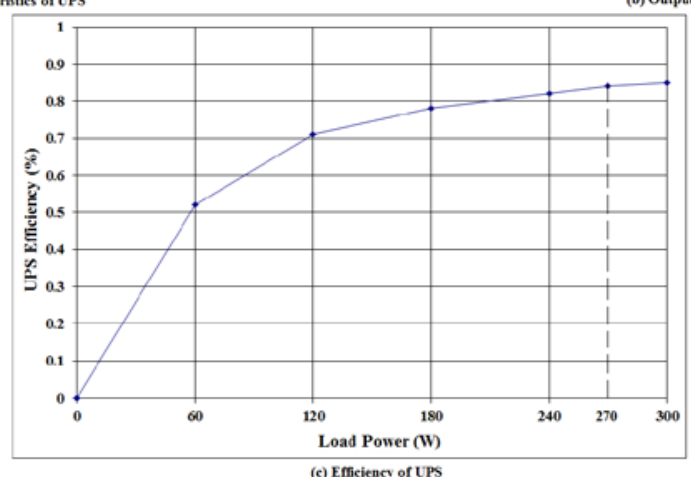

Fig. 18. Power, current and efficiency characteristics of UPS under the grid operating mode 

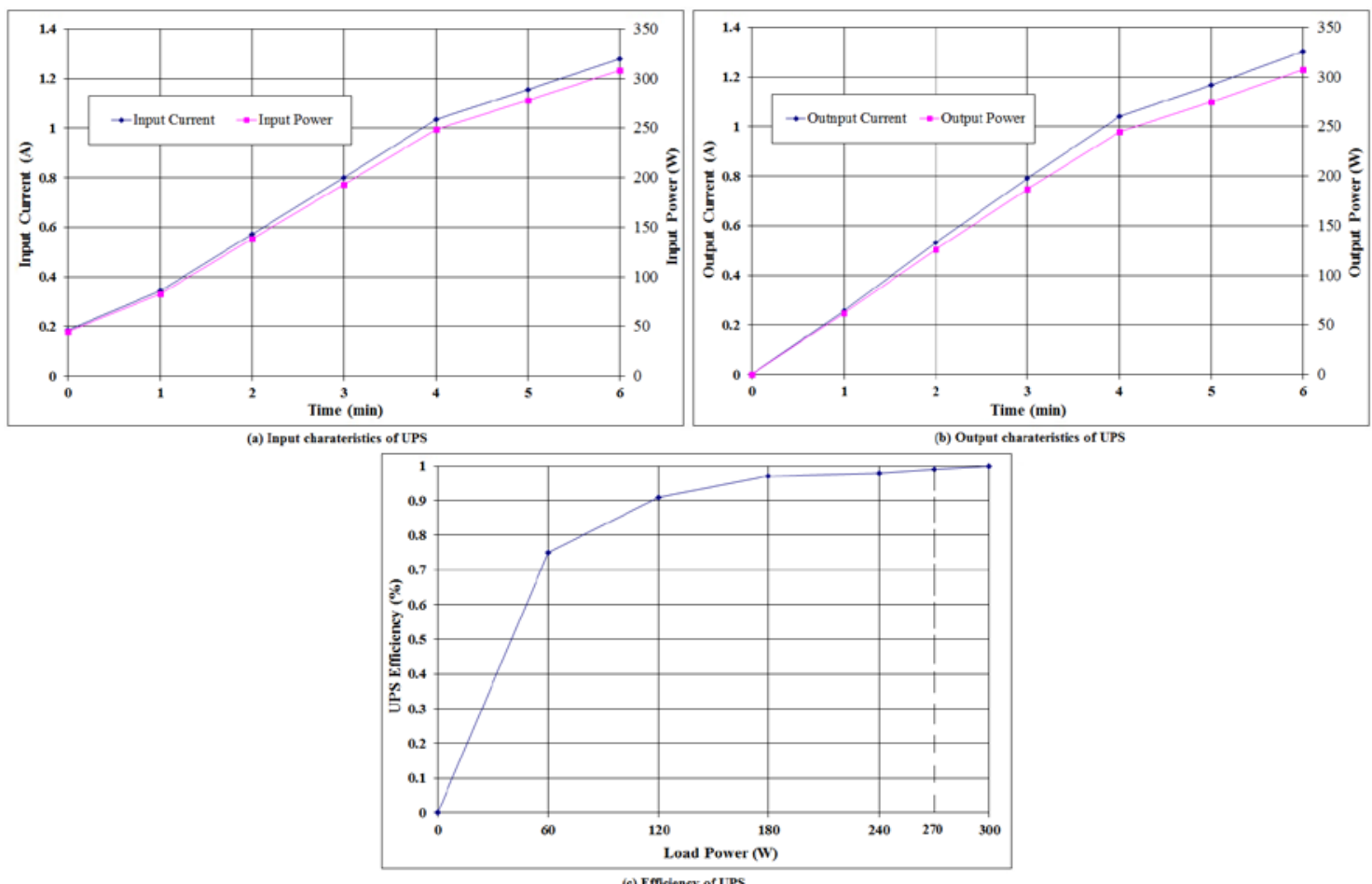

Fig. 19. Power, current and efficiency characteristics of UPS under the bypass operating mode 

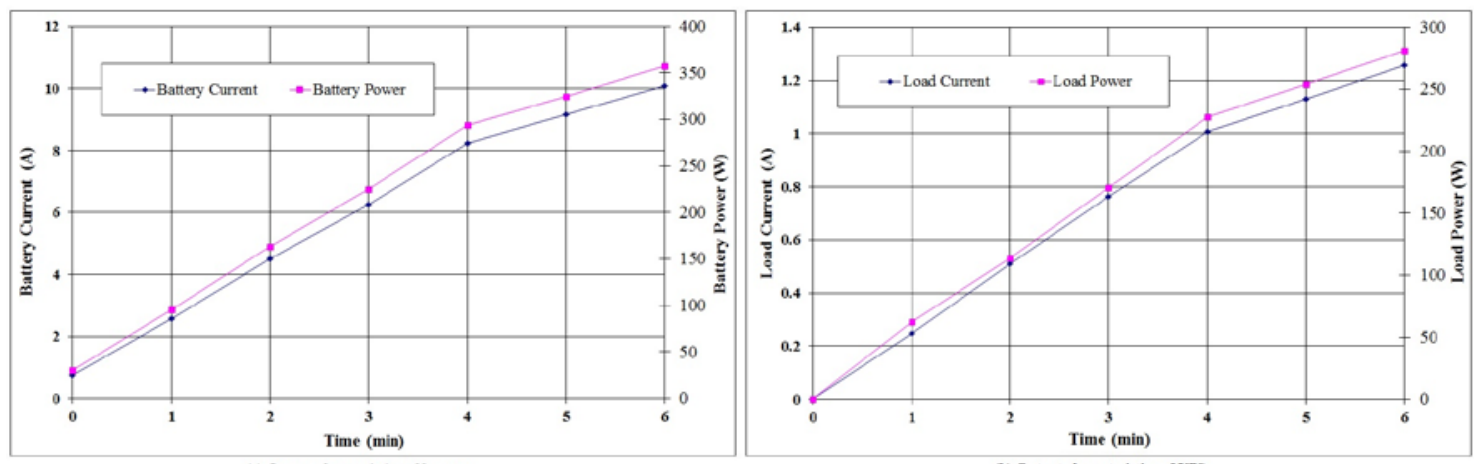

(a) Output charateristics of battery

(b) Outpet characteristics of UPS

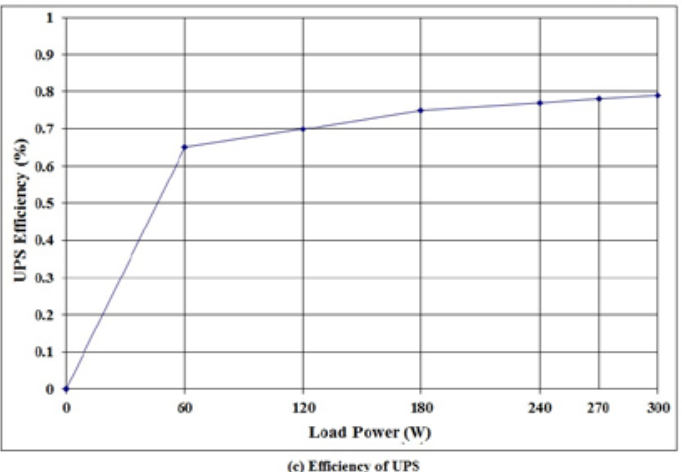

Fig. 20. Power, current and efficiency characteristics of battery and UPS under the battery operating

mode 

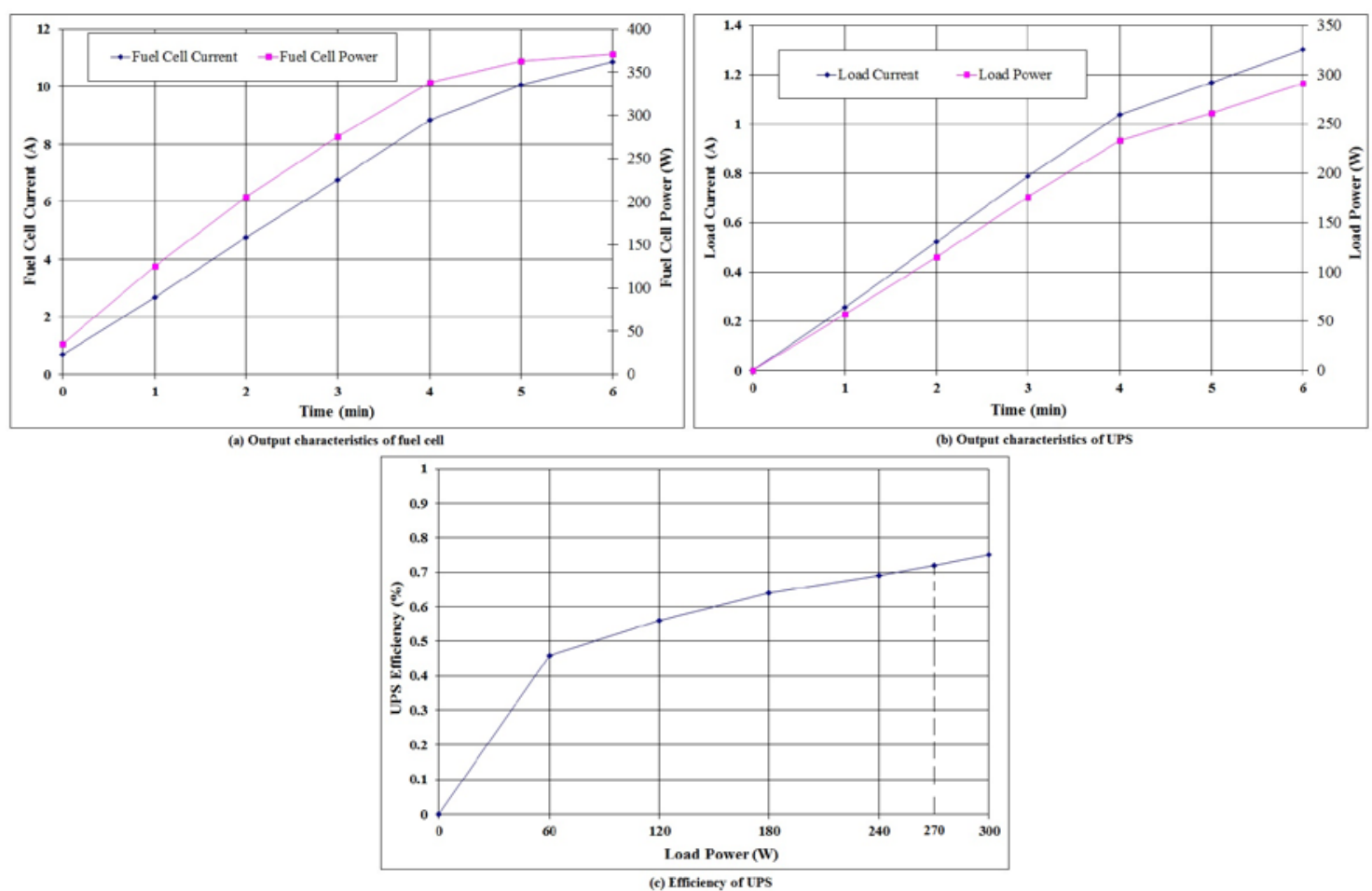

Fig. 21. Power, current and efficiency characteristics of PEMFC and UPS under the FC operating mode 


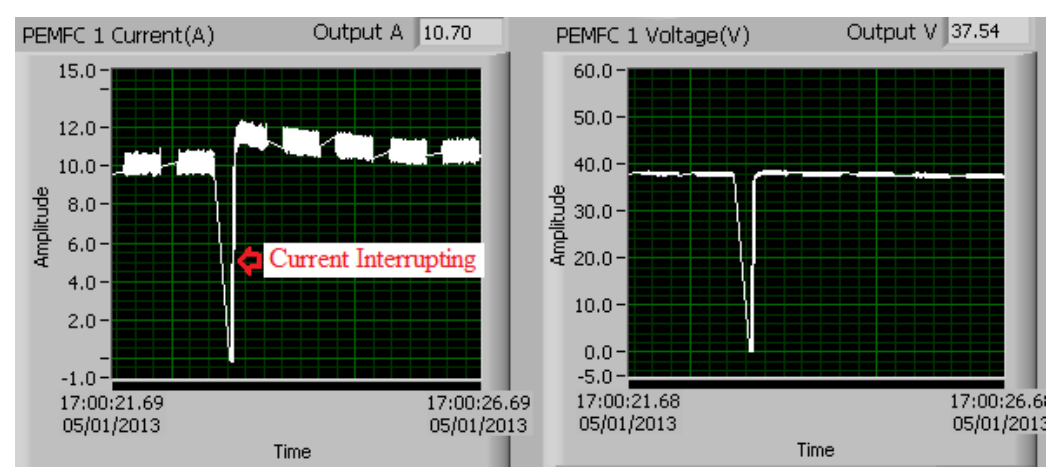

Fig. 22. Voltages and currents waveform of PEMFC operating mode when using the current interrupting 


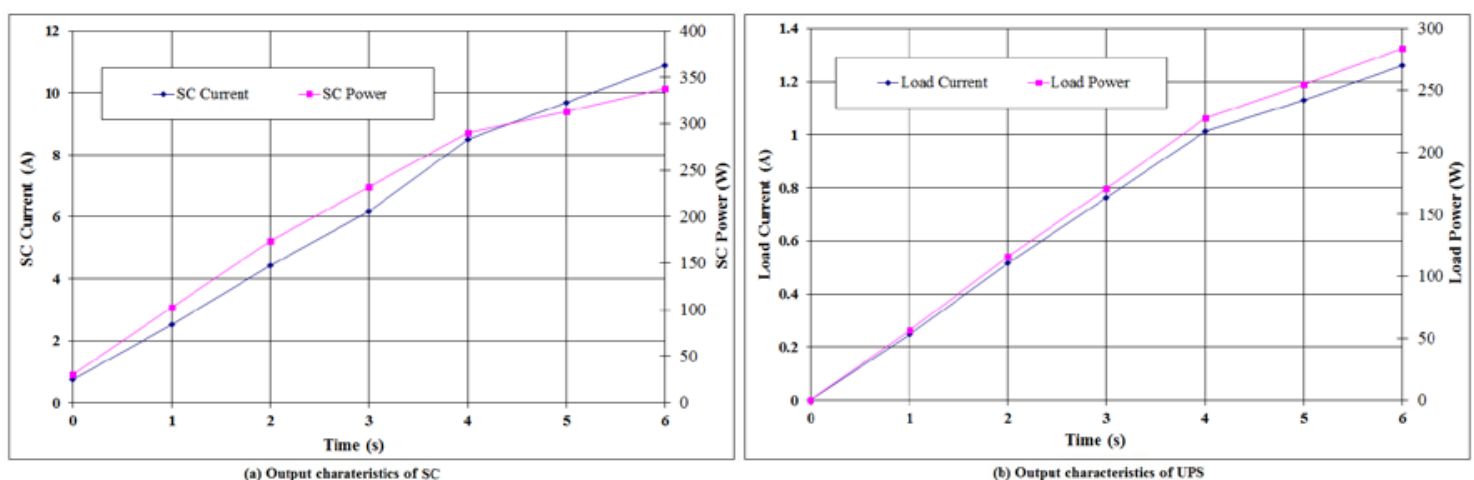

$\begin{array}{ll}\text { (a) Output charateristics of SC } & \text { (b) Output eharacteristics of LPS }\end{array}$

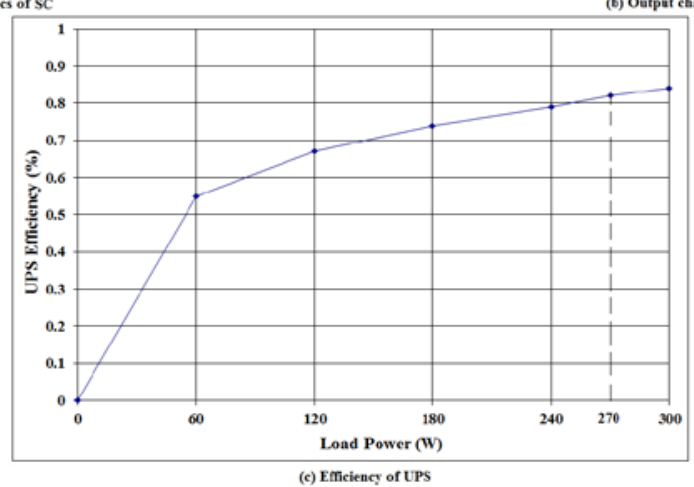

Fig. 23. Power, current and efficiency characteristics of SC and UPS under the SC operating mode 